\title{
A SCHUR METHOD FOR SOLVING ALGEBRAIC RICCATI EQUATIONS
}

Alan J. Laub

Lave

Laboratory for Information and Decision Systems

Formerly

Electronic Systems Laboratory

MASSACHUSETTS INSTITUTE OF TECHNOLOGY, CAMBRIDGE, MASSACHUSETTS 02139 
A SCHUR METHOD FOR SOLVING ALGEBRAIC RICCATI EQUATIONS*

by

Alan J. Laub**

\begin{abstract}
In this paper a new algorithm for solving algebraic Riccati equations (both continuous-time and discrete-time versions) is presented. The method studied is a variant of the classical eigenvector approach and uses instead an appropriate set of schur vectors thereby gaining substantial numerical advantages. Complete proofs of the Schur approach are given as well as considerable discussion of numerical issues. The method is apparently quite numerically stable and performs reliably on systems with dense matrices up to order 100 or so, storage being the main limiting factor.
\end{abstract}

*This research was supported by the U.S. Energy Research and Development Agency under contract ERDA-E (49-18)-2087.

**Laboratory for Information and Decision Systems, Rm. 35-331, Massachusetts Institute of Technology, Cambridge, MA 02139; ph.: (617)-253-2125. 


\section{Introduction}

In this paper a new algorithm for solving algebraic Riccati equations (both continuous-time and discrete-time versions) is presented. These equations play fundamental roles in the analysis, synthesis, and design of linear-quadratic-Gaussian control and estimation systems as well as in many other branches of applied mathematics. It is not the purpose of this paper to survey the extensive literature available for these equations but, rather, we refer the reader to, for example, [1], [2], [3], [4], and [5] for references. Nor is it our intention to investigate any but the unique (under suitable hypotheses) symmetric, nonnegative definite solution of an algebraic Riccati equation even though the algorithm to be presented does also have the potential to produce other solutions. For further reference to the "geometry" of the Riccati equation we refer to $[3],[6]$, and [7].

The method studied here is a variant of the classical eigenvector approach to Riccati equations, the essentials of which date back to at least von Escherich in 1898 [8]. The approach has also found its way into the control literature in papers by, for example, MacFarlane [9], Potter [10], and Vaughn [11]. Its use in that literature is often associated with the name of Potter. However, the use of eigenvectors is often highly unsatisfactory from a numerical point of view and the present method uses the so-called and much more numerically attractive Schur vectors to get a basis for a certain subspace of interest in the problem.

Other authors such as Fath [12] and willems [3], to name two, have also noted that any basis of the subspace would suffice but the specific

\section{6}


use of Schur vectors was inhibited by a not-entirely-straightforward problem of ordering triangular canonical forms - a problem which is discussed at length in the sequel. The paper by Fath is very much in the spirit of the work presented here and is one of the very few in the literature which seriously addresses numerical issues.

One of the best summaries of the eigenvector approach to solving algebraic Riccati equations is the work of Martensson [13]. This work extends [10] to the case of "multiple closed-Ioop eigenvalues". It will be shown in the sequel how the present approach recovers all the theoretical results of [10] and [13] while providing significant numerical advantages.

Most numerical comparisons of Riccati algorithms tend to definitely favor the standard eigenvector approach - its numerical difficulties notwithstanding - over other approaches such as Newton's method [14] or methods based on integrating a Riccati differential equation. Typical of such comparisons are [7], [15], and [16]. It will be demonstrated in this paper that if you previously liked the eigenvector approach, you will like the Schur vector approach at least twice as much. This statement, while somewhat simplistic, is based on the fact that a schur vector approach provides a substantially more efficient, useful, and reliable technique for numerically solving algebraic Riccati equations. The method is intended primarily for the solution of dense, moderatesized equations (say, order $\leq 100$ ) rather than large, sparse equations. While the algorithm in its present state offers much scope for improvement, it still represents an order-of-magnitude improvement over current methods for solving algebraic Riccati equations.

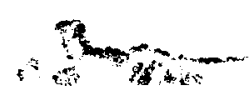


Briefly, the rest of the paper is organized as follows. This section is concluded with some notation and linear algebra review. In Sections 2 and 3 the continuous-time and discrete-time Riccati equations, respectively, are treated. In section 4 numerical issues such as algorithm implementation, balancing, scaling, operation counts, timing, storage, stability, and conditioning are considered. In section 5 we emphasize the advantages of the schur vector approach and make some further general remarks. Six examples are given in section 6 and some concluding remarks are made in Section 7.

\subsection{Notation}

Throughout the paper $A \in \mathbb{F}^{\mathrm{mxn}}$ will denote an mxn matrix with coefficients in a field $\mathbb{F}$. The field will usually be the real numbers $\mathbb{R}$ or the complex numbers $C$. The notations $A^{T}$ and $A^{H}$ will denote transpose and conjugate transpose, respectively, while $A^{-T}$ will denote $\left(A^{T}\right)^{-1}=\left(A^{-1}\right)^{T}$. The notation $A^{+}$will denote the Moore-Penrose pseudoinverse of the matrix $A$. For $A \in \mathbb{R}^{n \times n}$ its spectrum (set of $n$ eigenvalues) will be denoted by $\sigma(A)$. When a matrix $A \in \mathbb{R}^{2 \mathrm{n} \times 2 \mathrm{n}}$ is partitioned into four $\mathrm{nxn}$ blocks as

$$
A=\left(\begin{array}{ll}
A_{11} & A_{12} \\
A_{21} & A_{22}
\end{array}\right)
$$

we shall frequently refer to the individual blocks $A_{i j}$ without further t. discussign. 


\subsection{Linear Algebra Review}

Definition 1: $A \in \mathbb{R}^{\mathrm{nxn}}$ is orthogonal if $A^{\mathrm{T}}=\mathrm{A}^{-1}$.

Definition 2: $A \in \mathbb{C}^{\text {nxn }}$ is unitary if $A^{H}=A^{-1}$.

Let $J=\left(\begin{array}{cc}0 & I \\ -I & 0\end{array}\right) \in \mathbb{R}^{2 n \times 2 n}$ where $I$ denotes the $n^{t h}$ order identity matrix. Note that $\mathrm{J}^{\mathrm{T}}=\mathrm{J}^{-1}=-\mathrm{J}$.

Definition 3: $A \in \mathbb{R}^{2 n \times 2 n}$ is Hamiltonian if $J^{-1} A^{T} J=-A$.

Definition 4: $A \in \mathbb{R}^{2 \mathrm{n} \times 2 \mathrm{n}}$ is symplectic if $\mathrm{J}^{-1} \mathrm{~A}^{\mathrm{T}} \mathrm{J}=\mathrm{A}^{-1}$.

Hamiltonian and symplectic matrices are obviously closely related. For a discussion of this relationship and a review of "symplectic algebra" see [17], [18]. We will use the following two theorems from symplectic algebra. Their proofs (see [18]) are trivial (and hence will be omitted).

Theorem I: 1. Let $A \in \mathbb{R}^{2 \mathrm{n} \times 2 \mathrm{n}}$ be Hamiltonian. Then $\lambda \in \sigma(\mathrm{A})$ implies $-\lambda \in \sigma(A)$ with the same multiplicity. 2. Let $A \in \mathbb{R}^{2 n \times 2 n}$ be symplectic. Then $\lambda \in \sigma(A)$ implies $\frac{1}{\lambda} e \sigma(A)$ with the same multiplicity.

There is a relationship between the right and left eigenvectors of these symplectically associated eigenvalues. See [18] for details.

Theorem 2: Let $A \in \mathbb{I}^{2 \mathrm{n} \times 2 \mathrm{n}}$ be Hamiltonian (or symplectic). Let $U \in \mathbb{R}^{2 \mathrm{n} \times 2 \mathrm{n}}$ be symplectic. Then $\mathrm{U}^{-1} \mathrm{AU}$ is Hamiltonian (or symplectic).

Finally, we need two theorems from classical similarity theory which form the theoretical cornerstone of modern numerical linear algebra. See [19], for example, for a textbook treatment. 
Theorem 3 (Schur canonical form) : Let $A \in \mathbb{R}^{\mathrm{n \times n}}$ have eigenvalues $\lambda_{1}, \ldots, \lambda_{n}$. Then there exists a unitary similarity transformation $U$ such that $U^{\mathrm{H}} A U$ is upper triangular with diagonal elements $\lambda_{1}, \ldots, \lambda_{n}$ in that order.

In fact, it is possible to work only over $\mathbb{R}$ by reducing to quasiupper-triangular form with $2 \times 2$ blocks on the (block) diagonal corresponding to complex conjugate eigenvalues and $1 \times 1$ blocks corresponding to the real eigenvalues. We refer to this canonical form as the real schur form (RSF) or the Murnaghan-Wintner [20] canonical form.

Theorem 4 (RSF): Let $A \in \mathbb{R}^{\mathrm{nxn}}$. Then there exists an orthogonal similarity transformation $U$ such that $U^{\mathrm{T}} \mathrm{AU}$ is quasi-upper-triangular. Moreover, $\mathrm{U}$ can be chosen so that the $2 \times 2$ and $1 \times 1$ diagonal blocks appear in any desired order.

If in Theorem 4 we partition $U^{\mathrm{T}}$ AU into $\left(\begin{array}{cc}\mathrm{S}_{11} & \mathrm{~S}_{12} \\ 0 & \mathrm{~S}_{22}\end{array}\right)$ where $\mathrm{S}_{11} \in \mathbb{R}^{\mathrm{kxk}}$, $0<k \leq n$, we shall refer to the first $k$ vectors of $\mathrm{U} \mathrm{as}^{22}$ the Schur vectors corresponding to $\sigma\left(S_{11}\right) \subseteq \sigma(A)$. The Schur vectors corresponding to the eigenvalues of $\mathrm{S}_{11}$ span the eigenspace corresponding to those eigenvalues even when some of the eigenvalues are multiple (see [21]). We shall use this property heavily in the sequel. 


\section{The Continuous-Time Algebraic Riccati Equation}

In this section we shall present a method for using a certain set of Schur vectors to solve (for $\mathrm{x}$ ) the continuous-time algebraic Riccati equation

$$
F^{T} X+X F-X G X+H=0
$$

All matrices are in $\mathbb{R}^{\mathrm{nxn}}$ and $\mathrm{G}=\mathrm{G}^{\mathrm{T}} \geq 0, \mathrm{H}=\mathrm{H}^{\mathrm{T}} \geq 0$.

It is assumed that $(F, B)$ is a stabilizable pair [1] where $B$ is a full-rank factorization (FRF) of $\mathrm{G}\left(\right.$ i.e., $\mathrm{BB}^{\mathrm{T}}=\mathrm{G}$ and $\operatorname{rank}(\mathrm{B})=\operatorname{rank}(\mathrm{G})$ ) and $(C, F)$ is a detectable pair [1] where $C$ is a FRF of $H$ (i.e., $C^{T} C=H$ and $\operatorname{rank}(C)=\operatorname{rank}(H))$. Under these assumptions, (1) is known to have a unique nonnegative definite solution [1]. There are, of course, many other solutions to (1) but for the algorithm presented here the emphasis will be on computing the nonnegative definite one.

Now consider the Hamiltonian matrix

$$
Z=\left(\begin{array}{cc}
F & -G \\
-H & -F^{T}
\end{array}\right) \quad \in \mathbb{R}^{2 n \times 2 n}
$$

Our assumptions guarantee that $\mathrm{Z}$ has no pure imaginary eigenvalues. Thus by Theorem 4 we can find an orthogonal transformation $U \in \mathbb{R}^{2 \mathrm{n} \times 2 \mathrm{n}}$ which puts $z$ in RSF:

$$
\mathrm{U}^{\mathrm{T}} \mathrm{ZU}=\mathrm{S}=\left(\begin{array}{ll}
\mathrm{S}_{11} & \mathrm{~S}_{12} \\
0 & \mathrm{~S}_{22}
\end{array}\right)
$$

where $s_{i j} \in \mathbb{R}^{n \times n}$. It is possible to arrange, moreover, that the real parts of the spectrum of $\mathrm{S}_{11}$ are negative while the real parts of the spectrum of $\mathrm{S}_{22}$ are positive. $\mathrm{U}$ is conformably partitioned into four nxn blocks: 


\section{$-8-$}

$U=\left(\begin{array}{ll}U_{11} & U_{12} \\ U_{21} & U_{22}\end{array}\right)$

We then have the following theorem.

Theorem 5: With respect to the notation and assumptions above:

1. $U_{11}$ is invertible and $\mathrm{x}=\mathrm{U}_{21} \mathrm{U}_{11}^{-1}$ solves (1).

2. $\sigma\left(S_{11}\right)=\sigma(F-G X)=$ the "closed-1oop" spectrum.

3. $x=x^{T}$.

4. $x \geq 0$.

Proof:

1. We first prove that $\mathrm{U}_{11}$ is invertible. To avoid complicating the proof unnecessarily by having to consider $2 \times 2$ blocks of $\mathrm{S}_{11}$, we will for simplicity assume that $s \in \mathbb{C}^{2 \mathrm{n} \times 2 \mathrm{n}}$ is upper triangular and $U$ is unitary. Suppose $U_{11} \in \mathbb{C}^{\mathrm{nxn}}$ is singular. Without any loss of generality, we may assume that $U_{11}$ is of the form $\left(0, \hat{U}_{11}\right)$ where $\hat{U}_{11} \in \mathbb{c}^{\mathrm{nx}(\mathrm{n}-1)}$. Thus, we have

$$
\left(\begin{array}{cc}
F & -G \\
-H & -F^{T}
\end{array}\right)\left(\begin{array}{l}
0 \\
u
\end{array}\right)=\left(\begin{array}{l}
0 \\
u
\end{array}\right) \cdot(-\lambda)
$$

where $u \in \mathbb{C}^{\mathrm{nxl}}$ and $(-\lambda)$ with $\operatorname{Re} \lambda>0$ is the upper left element of $\mathrm{s}$. But then for any $x$ we have

$$
\begin{aligned}
(F-G X)^{T} u & =F^{T} u-x^{T} G u \\
& =\lambda u \quad \text { by }(5) .
\end{aligned}
$$


However, we also have $F^{T} u=\lambda u$ by (5). Thus we have an eigenvalue $\lambda$ of $\mathrm{F}$ with positive real part which is uncontrollable. This contradicts the assumption of stabilizability so $\mathrm{U}_{11}$ must be invertible. We now show that $\mathrm{X}=\mathrm{U}_{21} \mathrm{U}_{11}^{-1}$ solves (1). Simply substitute into (1): $F^{T} X+X F-X G X+H \equiv-(I, X) J Z\left(\begin{array}{l}I \\ X\end{array}\right)$

$$
\begin{aligned}
& =\left(U_{21} U_{1 I}^{-1},-I\right) z\left(\begin{array}{c}
I \\
U_{21} U_{11}^{-1}
\end{array}\right) \\
& =\left(U_{21} U_{11}^{-1},-I\right) z\left(\begin{array}{c}
U_{11} \\
U_{2 I}
\end{array}\right) U_{11}^{-1} \\
& =\left(U_{21} U_{I 1}^{-1},-I\right)\left(\begin{array}{c}
U_{11} \\
U_{21}
\end{array}\right) S_{11} U_{11}^{-1} \text { from (3) }
\end{aligned}
$$

$$
=0 \text {. }
$$

$$
\text { 2. } \operatorname{From}\left(\begin{array}{cc}
F & -G \\
-H & -F^{T}
\end{array}\right)\left(\begin{array}{c}
U_{11} \\
U_{21}
\end{array}\right)=\left(\begin{array}{c}
U_{11} \\
U_{21}
\end{array}\right) s_{11}
$$

we have $\mathrm{U}_{11} \mathrm{~S}_{11}=\mathrm{FU}_{11}-\mathrm{GU}_{21}$

$$
=(F-G X) U_{11}
$$

Thus $U_{11}^{-1}(F-G X) U_{11}=S_{11}$ so $\sigma\left(S_{11}\right)=\sigma(F-G X)$.

$$
\text { 3. Let } \mathrm{Y}=\mathrm{U}_{11}^{\mathrm{T}} \mathrm{U}_{21} \text {. }
$$

Then

$$
\mathrm{X}=\mathrm{U}_{11}^{-\mathrm{T}} \mathrm{YU}_{11}^{-1}
$$


so to prove that $X$ is symmetric it clearly suffices to show that $Y$ is symmetric, i.e., $U_{11}^{T} U_{21}-U_{21}^{T} U_{11}=0$.

Now consider the skew-symmetric, orthogonal matrix $M=U^{T} J U$. Using the fact that $z$ is Hamiltonian, it is easy to show that

$$
S^{T} M=-M S
$$

where $S$ was given in (3). Thus $S_{11}^{T} M_{11}+M_{11} S_{11}=0$. But since $s_{11}$ is stable, it follows from classical Lyapunov theory (see, e.g., [22]) that $M_{11}=0$. But $M_{11}=U_{11}^{T} U_{21}-U_{21}^{T} U_{11}$ so $U_{11}^{T} U_{21}=U_{21}^{T} U_{11}$.

Remark: It can be shown that the matrix $M$ is of the general form

$$
M=\left(\begin{array}{cc}
0 & M_{12} \\
-M_{12}^{T} & 0
\end{array}\right) \text { where } M_{12} \text { is orthogonal. }
$$

4. From (6) and (7) it clearly suffices to prove that $U_{11}^{\mathrm{T}} \mathrm{U}_{21} \geq 0$. Define

$$
V(t)=\left(\begin{array}{c}
U_{11} \\
u_{21}
\end{array}\right) e^{t S_{11}}
$$

Note that $V(0)=\left(\begin{array}{c}U_{11} \\ U_{21}\end{array}\right)$ while $\lim _{t \rightarrow+\infty} V(t)=\left(\begin{array}{l}0 \\ 0\end{array}\right)$ since $s_{11}$ is stable. Then

$$
\begin{aligned}
\dot{v}(t) & =\left(\begin{array}{c}
U_{11} \\
U_{21}
\end{array}\right) s_{11} e^{t s_{11}} \\
& =z\left(\begin{array}{c}
U_{11} \\
u_{21}
\end{array}\right) e^{t s_{11}} \quad \text { by (3) } \\
& =z v(t) .
\end{aligned}
$$


Now let $W(t)=V^{T}(0) L V(0)-V^{T}(t) L V(t)$ where $L=\left(\begin{array}{ll}0 & I \\ 0 & 0\end{array}\right)$. Then

$$
\begin{aligned}
W(t) & =-\int_{0}^{t} \frac{d}{d s}\left[V^{T}(s) L V(s)\right] d s \\
& =-\int_{C}^{t} v^{T}(s)\left[z^{T} L+L Z\right] V(s) d s \\
& =-\int_{C}^{t} v^{T}(s)\left[\begin{array}{cc}
-H & 0 \\
0 & -G
\end{array}\right] V(s) d s \\
& \geq 0 \text { for all } t \geq 0 .
\end{aligned}
$$

Thus $\lim _{t \rightarrow+\infty} W(t)=V^{T}(0) \operatorname{LV}(0)=U_{11}^{T} U_{21} \geq 0$

This completes the proof of the theorem.

Further discussion of this theorem and computational considerations are deferred until section 4. 


\section{The Discrete-Time Algebraic Riccati Equation}

In this section we shall present an analogous method using certain Schur vectors to solve the discrete-time algebraic Riccati equation

$$
F^{T} X F-X-F^{T} X G_{1}\left(G_{2}+G_{1}^{T} X G_{1}\right)^{-1} G_{1}^{T} X F+H=0
$$

Here $F, H, X \in \mathbb{R}^{n \times n}, G_{1} \in \mathbb{R}^{n \times m}, G_{2} \in \mathbb{R}^{m \times m}$, and $H=H^{T} \geq 0, G_{2}=G_{2}^{T}>0$. Also, $m \leq n$. The details of the method for this equation are sufficiently different from the continuous-time case that we shall explicitly present most of them.

It is assumed that $\left(F, G_{1}\right)$ is a stabilizable pair and that $(C, F)$ is a detectable pair where $\mathrm{C}$ is a FRF of $\mathrm{H}$ (i.e., $\mathrm{C}^{\mathrm{T}} \mathrm{C}=\mathrm{H}$ and $\operatorname{rank}(\mathrm{C})=\operatorname{rank}(\mathrm{H})$ ). We also assume that $\mathrm{F}$ is invertible - a common assumption on the openloop dynamics of a discrete-time system [23]. The details for the case when $F$ is singular can be found in Appendix 1.

Under the above assumptions ( 8 ) is known to have a unique nonnegative definite solution [23] and the method proposed below will be directed towards finding that solution.

Setting $G=G_{1} G_{2}^{-1} G_{1}^{T}$ we consider this time the symplectic matrix

$$
z=\left(\begin{array}{cr}
F+G F^{-T} & -G F^{-T} \\
-F^{-T} & F^{-T}
\end{array}\right)
$$

Our assumptions guarantee that $z$ has no eigenvalues on the unit circle. By Theorem 4 we can find an orthogonal transformation $U \in \mathbb{R}^{2 \mathrm{n} \times 2 \mathrm{n}}$ which puts $\mathrm{Z}$ in RSF:

\footnotetext{
* Note that an alternate equivalent form of (8) when $\mathrm{x}$ is invertible is: $F^{T}\left(X^{-1}+G_{1} G_{2}^{-1} G_{1}^{T}\right)^{-1} F-X+H=0$
} 
$U^{T} \mathrm{ZU}=\mathrm{S}=\left(\begin{array}{ll}\mathrm{S}_{11} & \mathrm{~S}_{12} \\ 0 & \mathrm{~S}_{22}\end{array}\right)$

where $S_{i j} \in \mathbb{R}^{\mathrm{nxn}}$.

It is possible to arrange, moreover, that the spectrum of $s_{11}$ lies inside the unit circle while the spectrum of $S_{22}$ lies outside the unit circle. Again U is partitioned conformably. We then have the following theorem.

Theorem 6: With respect to the notation and assumptions above:

1. $\mathrm{U}_{11}$ is invertible and $\mathrm{x}=\mathrm{U}_{21} \mathrm{U}_{11}^{-1}$ solves (8).

2. $\sigma\left(S_{11}\right)=\sigma\left(F-G_{1}\left(G_{2}+G_{1}^{T} X G_{1}\right)^{-1} G_{1}^{T} X F\right)$

$=\sigma\left(F-G F^{-T}(X-H)\right)$

$=\sigma\left(F-G\left(X^{-1}+G\right)^{-1} F\right)$ when $x$ is invertible

= the "closed-loop" spectrum.

3. $x=x^{T}$.

4. $x \geq 0$

Proof :

1. We proceed as in the proof of Theorem 5. Again we assume that $U_{11}$ is singular and of the form $U_{11}=\left(0, \hat{U}_{11}\right)$ where $\hat{v}_{11} \in \mathbb{c}^{\mathrm{nx}(n-1)}$. Then since $U^{T} z^{-1} U=s^{-1}$ we have

$$
\left(\begin{array}{ll}
\mathrm{F}^{-1} & \mathrm{~F}^{-1} \mathrm{G} \\
\mathrm{HF}^{-1} & \mathrm{~F}^{\mathrm{T}}+\mathrm{HF}^{-1} \mathrm{G}
\end{array}\right)\left(\begin{array}{l}
0 \\
\mathrm{u}
\end{array}\right)=\left(\begin{array}{l}
0 \\
\mathrm{u}
\end{array}\right) \lambda
$$

where $u \in \mathbb{C}^{\mathrm{nxl}}$ and $|\lambda|>1$. But then for any $\mathrm{x}$ we have 


$$
\begin{aligned}
\left(F-G F^{-T}(X-H)\right)^{T} u & =\left(F^{T}+H F^{-1} G\right) u-x^{T} F^{-1} G u \\
& =\lambda u
\end{aligned}
$$

by (11). However, we also have $F^{T} u=\lambda u$ by (11). Thus we have $\lambda \in \sigma(F)$ with $|\lambda|>1$ which is uncontrollable. This contradicts the assumption of stabilizability so $\mathrm{U}_{11}$ must be invertible. To show that $\mathrm{x}=\mathrm{U}_{21} \mathrm{U}_{11}^{-1}$ solves (8) we have:

$$
\begin{aligned}
& F^{T} X F-X-F^{T} X G_{1}\left(G_{2}+G_{1}^{T} X G_{1}\right)^{-1} G_{1}^{T} X F+H \\
& \equiv F^{T} X F-X-F^{T} X G F^{-T}(X-H)+H \\
& \equiv-F^{T}(I, X) J Z\left(\begin{array}{l}
I \\
X
\end{array}\right) \\
& =-F^{T}\left(-U_{2 I} U_{1 I}^{-1}, I\right) \quad z\left(\begin{array}{c}
U_{1 I} \\
U_{2 I}
\end{array}\right) U_{1 I}^{-I} \\
& =-F^{T}\left(-U_{21} U_{1 I}^{-1}, I\right)\left(\begin{array}{c}
U_{11} \\
U_{21}
\end{array}\right) S_{11} U_{1 I}^{-1} \quad \text { from (10) } \\
& =0 \text {. } \\
& \text { 2. } \operatorname{From}\left(\begin{array}{cc}
\mathrm{F}+\mathrm{GF}^{-\mathrm{T}_{\mathrm{H}}} & -\mathrm{GF}^{-\mathrm{T}} \\
-\mathrm{F}^{-\mathrm{T}_{\mathrm{H}}} & \mathrm{F}^{-\mathrm{T}}
\end{array}\right)\left(\begin{array}{c}
\mathrm{U}_{11} \\
\mathrm{U}_{21}
\end{array}\right)=\left(\begin{array}{c}
\mathrm{U}_{11} \\
\mathrm{U}_{21}
\end{array}\right) \mathrm{S}_{11}
\end{aligned}
$$

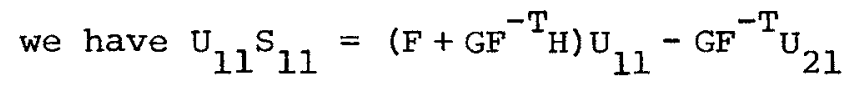

$$
=\left(F-G F^{-T}(X-H)\right) U_{11} \text {. }
$$

Thus $\sigma\left(S_{I l}\right)=\sigma\left(F-G^{-T}(X-H)\right)$. The other equalities follow by wellknown matrix identities. 
3. Let $\mathrm{Y}=\mathrm{U}_{11}^{\mathrm{T}} \mathrm{U}_{21}$. Since $\mathrm{X}=\mathrm{U}_{11}^{-\mathrm{T}} \mathrm{YU}_{11}^{-1}$ it suffices, as in Theorem 5, to prove that $Y$ is symmetric. The proof is essentially the same:

since $\mathrm{z}$ is symplectic we have

$$
S^{T} M=-M S^{-1}
$$

where $M=U^{T} J U$ and $S$ was given in (10). Then $S_{11}^{T} M_{11} S_{11}+M_{11}=0$ whence $M_{11}=0$ by classical Lyapunov theory. But $\mathrm{M}_{11}=\mathrm{U}_{11}^{\mathrm{T}} \mathrm{U}_{21}-\mathrm{U}_{21}^{\mathrm{T}} \mathrm{U}_{11}$ so symmetry follows.

4. As in Theorem 5 it suffices to prove that $U_{11}^{\mathrm{T}} \mathrm{U}_{21} \geq 0$. Define $V(k)=\left(\begin{array}{c}U_{11} \\ U_{21}\end{array}\right) s_{11}^{k}$. Note that $V(0)=\left(\begin{array}{c}U_{11} \\ U_{21}\end{array}\right)$ while $\lim _{k \rightarrow+\infty} v(k)=\left(\begin{array}{l}0 \\ 0\end{array}\right)$ since

$\mathrm{S}_{11}$ is stable. Then

$$
\begin{aligned}
V(k+1) & =\left(\begin{array}{c}
U_{11} \\
U_{21}
\end{array}\right) s_{11}^{k+1} \\
& =\operatorname{zV}(k)
\end{aligned}
$$

by $(10)$. Now let $W(k)=V^{T}(0) L V(0)-V^{T}(k) L V(k)$ where $L=\left(\begin{array}{ll}0 & I \\ 0 & 0\end{array}\right)$. Then

$$
\begin{aligned}
W(k) & =\sum_{j=0}^{k-1}\left[V^{T}(j) L V(j)-V^{T}(j+1) L V(j+1)\right] \\
& =\sum_{j=0}^{k-1} V^{T}(j)\left[L-z^{T} L Z\right] V(j) \\
& =\sum_{j=0}^{k-1} V^{T}(j)\left[\begin{array}{ll}
H+H F^{-1} G F^{-T} H & -H F^{-1} G F^{-T} \\
-F^{-1} G F^{-T} & F^{-1} G F^{-T}
\end{array}\right] V(j)
\end{aligned}
$$

Now, according to a theorem of Albert [24], a matrix

$$
A=\left(\begin{array}{ll}
A_{11} & A_{12}^{T} \\
A_{12} & A_{22}
\end{array}\right)
$$


with $A_{11}=A_{11}^{T} \in \mathbb{R}^{n \times n}, A_{22}=A_{22}^{T} \in \mathbb{R}^{m \times m}$ is nonnegative definite if and only if:
(i) $\mathrm{A}_{22} \geq 0$
(ii) $\mathrm{A}_{22} \mathrm{~A}_{22}^{+} \mathrm{A}_{12}=\mathrm{A}_{12}$

and

$$
\text { (iii) } \mathrm{A}_{11}-\mathrm{A}_{12}^{\mathrm{T}} \mathrm{A}_{22}^{+} \mathrm{A}_{12} \geq 0 \text {. }
$$

For the matrix $A=\left(\begin{array}{cc}\mathrm{H}+\mathrm{HEH} & -\mathrm{HE} \\ -\mathrm{EH} & \mathrm{E}\end{array}\right)$ where $\mathrm{E}=\mathrm{F}^{-\mathrm{I}_{\mathrm{GF}}}{ }^{-\mathrm{T}}$ we clearly have (i) satisfied. We also have (ii) satisfied since $\mathrm{EE}^{+}(-\mathrm{EH})=-\mathrm{EH}$ by an elementary defining property of the Moore-Penrose pseudoinverse [25]. Finally, to verify (iii) we note that

$$
\mathrm{H}+\mathrm{HEH}-(-\mathrm{HE}) \mathrm{E}^{+}(-\mathrm{EH})=\mathrm{H} \geq 0 \text {. }
$$

Thus $W(k) \geq 0$ for all $k \geq 0$ so

$$
\lim _{k \rightarrow+\infty} W(k)=V^{T}(0) L V(0)=U_{1 I}^{T} U_{21} \geq 0
$$

This completes the proof of the theorem.

We now turn to some general numerical considerations regarding the schur vector approach. 


\section{Numerical Considerations}

There are two steps to the Schur vector approach. The first is reduction of a $2 \mathrm{n} \times 2 \mathrm{n}$ matrix to an ordered real Schur form; the second is

the solution of an $n \frac{t h}{-}$ order linear matrix equation. We shall discuss these in the context of the continuous-time case noting differences for the discrete-time case where appropriate.

\subsection{Algorithm Implementation}

It is well-known (see [21], for example) that the double Francis QR algorithm applied to a real general matrix does not guarantee any special order for the eigenvalues on the diagonal of the Schur form. However, it is also known how the real schur form can be arbitrarily reordered via orthogonal similarities; see [21] for details. Thus any further orthogonal similarities required to ensure that $\sigma\left(s_{11}\right)$ in (3) lies in the left-half complex plane can be combined with the U initially used to get a RSF to get a final orthogonal matrix which effects the desired ordered RSF.

Stewart has recently published FORTRAN subroutines for calculating and ordering the RSF of a real upper Hessenberg matrix [26]. The $1 \times 1$ or $2 \times 2$ blocks are ordered so that the eigenvalues appear in descending order of magnitude along the diagonal. Stewart's software (HQR3) may thus be used directly if one is willing to first apply to the $z$ of (2) an appropriate bilinear transformation which maps the left-half-plane to the exterior of the unit circle. Since the transformed $z$ is an analytic function of $\mathrm{Z}$, the $U$ that reduces it to an ordered RSF - with half the eigenvalues outside the unit circle - is the desired U from which the 
solution of (1) may be constructed. Alternatively, Stewart's software can be modified to directly reorder a RSF by algebraic sign.

In the discrete-time case, HQR3 can be used directly by working with

$$
\mathrm{z}^{-1}=\left(\begin{array}{ll}
\mathrm{F}^{-1} & \mathrm{~F}^{-1} \mathrm{G} \\
\mathrm{HF}^{-1} & \mathrm{~F}^{\mathrm{T}}+\mathrm{HF}^{-1} \mathrm{G}
\end{array}\right) .
$$

The $U$ which puts $\sigma\left(S_{11}\right)$ outside the unit circle is thus the same $U$ which puts the upper left $\mathrm{nxn}$ block of the RSF of $\mathrm{z}$ inside the unit circle.

In summary then, to use HQR3 we would recommend using the following sequence of subroutines (or their equivalents):

BALANC to balance a real general matrix

ORTHES to reduce the balanced matrix to upper Hessenberg form using orthogonal transformations

ORTRAN to accumulate the transformations from the Hessenberg reduction

HQR3 to determine an ordered RSF from the Hessenberg matrix

BALBAK to backtransform the orthogonal matrix to a nonsingular matrix corresponding to the original matrix.

The subroutines BALANC, ORTHES, ORTRAN, BALBAK are all available in EISPACK [27].

The second step to be implemented is the solution of an $n \frac{\text { th }}{\text { order }}$ linear matrix equation

$$
\mathrm{XU}_{11}=\mathrm{U}_{21}
$$

to find $\mathrm{x}=\mathrm{U}_{21} \mathrm{U}_{11}^{-1}$. For this step we would recommend a good linear equation solver such as DECOMP and SOLVE available in [28] or the appropriate routines available in the forthcoming IINPACK [29]. A routine such 
as DECOMP computes the LU-factorization of $\mathrm{U}_{11}$ and SOLVE performs the forward and backward substitutions. A good estimate of the condition number of $\mathrm{U}_{11}$ with respect to inversion is available with good linear equation software and this estimate should be inspected. A badly conditioned $U_{11}$ usually results from a "badly conditioned Riccati equation". This matter will be discussed further in Section 4.4. While we have no analytical proof at this time, we have observed empirically that a condition number estimate on the order of $10^{t}$ for $U_{11}$ usually results in a loss of about $t$ digits of accuracy in $x$.

One final note on implementation. Since $\mathrm{X}$ is symmetric it is usually more convenient, with standard linear equation software, to solve the equation

$\begin{aligned} U_{11}^{T} x & =U_{21}^{T} \\ \text { to find } x & =U_{11}^{-T} U_{21}^{T}=U_{21} U_{11}^{-1} \text {. }\end{aligned}$

\subsection{Balancing and scaling}

Note that the use of balancing in the above implementation results in a nonsingular (but not necessarily orthogonal) matrix which reduces $Z$ to RSF. More specifically, suppose $P$ is a permutation matrix and $D$ is a diagonal matrix such that PD balances $z$, i.e.,

$$
\mathrm{D}^{-1} \mathrm{PZPD}=z_{b}
$$

where $z_{b}$ is the balanced matrix; see [30] for details. We then find an orthogonal matrix $U$ which reduces $z_{b}$ to ordered RSF:

$$
\mathrm{u}^{\mathrm{T}} \mathrm{z}_{\mathrm{b}} \mathrm{u}=\mathrm{s}
$$


Then PDU (produced by BALBAK) is clearly a nonsingular matrix which reduces $\mathrm{Z}$ to ordered RSF. The first $\mathrm{n}$ columns of PDU span the eigenspace corresponding to eigenvalues of $\mathrm{z}$ with negative real parts and that is the only property we require of the transformation. For simplicity in the sequel, we shall speak of the transformation reducing $z$ to RSF as simply an orthogonal matrix $U$ with the understanding that the more computationally attractive transformation is of the form PDU.

An alternative approach to direct balancing of $z$ is to attempt some sort of scaling in the problem which generates the Riccati equation. To illustrate, consider the linear optimal control problem of finding a feedback controller $\mathrm{u}(t)=\mathrm{Kx}(t)$ which minimizes the performance index

$$
J(u)=\int_{0}^{+\infty}\left[x^{T}(t) H x(t)+u^{T}(t) R u(t)\right] d t
$$

with plant constraint dynamics given by

$$
\dot{x}(t)=F x(t)+B u(t) ; \quad x(0)=x_{0} .
$$

We assume $H=H^{T} \geq 0, R=R^{T}>0$ and $(F, B)$ controllable, $(F, C)$ observable where $C^{T} C=H$ and $\operatorname{rank}(C)=\operatorname{rank}(H)$. Then the optimal solution is wellknown to be

$$
u(t)=-R^{-1} B^{T} X x
$$

where $\mathrm{X}$ solves the Riccati equation

$$
F^{T} X+X F-X B R^{-1}{ }_{B}^{T} X+H=0
$$

Now suppose we change coordinates via a nonsingular transformation $x(t)=T w(t)$. Then in terms of the new state $w$ our problem is to minimize 
$\int_{c}^{+\infty}\left[w^{T}(t)\left(T^{T} H T\right) w(t)+u^{T}(t) R u(t)\right] d t$

subject to

$\dot{w}(t)=\left(T^{-1} F T\right) w(t)+\left(T^{-1} B\right) u(t)$.

The Hamiltonian matrix $\mathrm{z}$ for this transformed system is now given

by

$$
Z_{W}=\left(\begin{array}{lc}
T^{-1} F T & -T^{-1}{ }_{B R}-1_{B} T_{T}-T \\
-T^{T} H T & -T^{T} T_{T} T^{-T}
\end{array}\right)
$$

and the associated solution $\mathrm{x}_{\mathrm{w}}$ of the transformed Riccati equation is related to the original $\mathrm{x}$ by $\mathrm{X}=\mathrm{T}^{-\mathrm{T}} \mathrm{X}_{\mathrm{w}} \mathrm{T}^{-1}$. One interpretation of $\mathrm{T}$ then is as a scaling transformation, a diagonal matrix, for example, in an attempt to "balance" the elements of $\mathrm{z}_{\mathrm{w}}$. Applying such a procedure, even in an ad hoc way, is frequently very useful from a computational point of view.

Another way to look at the above procedure is that $\mathrm{z}_{\mathrm{w}}$ is symplectically similar to $\mathrm{z}$ via the transformation $\left(\begin{array}{cc}\mathrm{T} & 0 \\ 0 & \mathrm{~T}^{-\mathrm{T}}\end{array}\right)$, i.e.. $\mathrm{z}_{\mathrm{w}}=\left(\begin{array}{cc}\mathrm{T} & 0 \\ 0 & \mathrm{~T}^{-\mathrm{T}}\end{array}\right)^{-1} \mathrm{z}\left(\begin{array}{cc}\mathrm{T} & 0 \\ 0 & \mathrm{~T}^{-\mathrm{T}}\end{array}\right)$

It is well-known that $\mathrm{z}_{\mathrm{w}}$ is again Hamiltonian (or symplectic in the discrete-time case) since the similarity transformation is symplectic. One can then pose the problem of transforming $\mathrm{z}$ by other, more elaborate symplectic similarities so as to achieve various desirable numerical properties or canonical forms. This topic for further research is presently being investigated. 


\subsection{Operation counts, Timing, and Storage}

We shall give approximate operation counts for the solution of $\mathrm{n}$ th order algebraic Riccati equations of the form (1) or (8). Each operation is assumed to be roughly equivalent to forming $a+(b \times c)$ where $a, b, c$ are floating point numbers. It is almost impossible to give an accurate operation count for the algorithm described above since so many factors are variable such as the ordering of the RSF. We shall indicate only a ballpark $O\left(n^{3}\right)$ figure.

Let us assume then that we already have at hand the $2 \mathrm{n} \times 2 \mathrm{n}$ matrix $z$ of the form (2) or (9). Note, however, that unlike forming $z$ in (2), $\mathrm{z}$ in (9) requires approximately $4 \mathrm{n}^{3}$ additional operations to construct, given only $F, G$, and $H$. This will turn out to be fairly negligible compared to the counts for the overall process. Furthermore, we shall give only order of $n^{3}$ counts for these rough estimates. The three main steps are:

$\begin{array}{ll}\text { (i) reduction of } \mathrm{z} \text { to upper Hessenberg from } & \frac{\text { Operations }}{3}(2 n)^{3} \\ \text { (ii) reduction of upper Hessenberg form to } \mathrm{RSF} & \geq 4 \mathrm{k}(2 \mathrm{n})^{3} \\ \text { (iii) solution of } \mathrm{XU}_{11}=\mathrm{U}_{21} & \frac{4}{3} \mathrm{n}^{3}\end{array}$

The number $\mathrm{k}$ represents the average number of $\mathrm{QR}$ steps required per eigenvalue and is usually over-estimated by 1.5 . We write $\geq 4 \mathrm{k}(2 \mathrm{n})^{3}$ since, in general, the reduction may need more operations if ordering is required. Using $k=1.5$ we see that the total number of operations required is at least $63 \mathrm{n}^{3}$. Should the ordering of the RSF require, say, 25\% more operations than the unordered RSF, we have 
a ballpark estimate of about $75 \mathrm{n}^{3}$ for the entire process. Timing estimates for steps (i) and (ii) may be obtained from [27] for a variety of computing environments. The additional time for balancing and for step (iii) would then add no more than about 5\% to those times while the additional time for ordering the RSF is variable, but typically adds no more than about 15\%. For example, adding $20 \%$ to the published figures [27] for an IBM 370/165 (a typical medium speed machine) under OS/360 at the University of Toronto using FORTRAN H Extended with Opt. $=2$ and double precision arithmetic, we can construct the following table:

\begin{tabular}{l|cccc}
$\begin{array}{c}\text { Riccati Equation } \\
\text { Order } \mathrm{n}=\end{array}$ & 10 & 20 & 30 & 40 \\
\hline CPU Time (Sec.) & 0.2 & 1.3 & 4.0 & 9.0
\end{tabular}

In fact, these times are in fairly close agreement with actual observed times for randomly chosen test examples of these orders. Note the approximately cubic behavior of time versus order.

Extrapolating these figures for a 64 th order equation (see Example 5 in section 6) one might expect a CPU-time in the neighborhood of $38 \mathrm{sec}$. In fact, for that particular example the time was approximately $34 \mathrm{sec}$.

It must be re-emphasized here that timing estimates derived as above are very approximate and depend on numerous factors in the actual computing environment as well as the particular input data. However, such estimates can provide very useful and quite reliable information if interpreted as providing essentially order of magnitude figures. 
With respect to storage considerations the algorithm requires $8 n^{2}+c n(c=a$ small constant) storage locations. This fairly large figure limits applicability of the algorithm to Riccati equations on the order of about 100 or less in many common computing environments. of course, CPU time becomes a significant factor for $\mathrm{n}>100$, also.

\subsection{Stability and Conditioning}

This section will be largely speculative in nature as very few hard results are presently available. A number of areas of continuing research will be described.

With respect to stability, the implementation discussed in section 4.1 consists of two effectively stable steps. The crucial step is the QR step and the present algorithm is probably essentially as stable as QR. The overall two step process is apparently quite stable numerically but we have no proof of that statement.

$$
\text { Concerning the conditioning of (1) (or (8)) almost no analytical }
$$

results are known. The study of (1) is obviously more complex than

the study of even the Lyapunov equation

$$
F^{T} X+X F+H=0
$$

where $\mathrm{H}=\mathrm{H}^{\mathrm{T}} \geq 0$. And yet very little numerical analysis is known for (12). In case $\mathrm{F}$ is normal, a condition number with respect to inversion of the Lyapunov operator $F X=F^{T} X+X F$ is easily shown to be given by

$$
\frac{\max _{i, j}\left|\lambda_{i}(F)+\lambda_{j}(F)\right|}{\min _{i, j}\left|\lambda_{i}(F)+\lambda_{j}(F)\right|} .
$$


But in the general case, a condition number in terms of $F$ rather than $F^{T} \otimes I+I \otimes F^{T}(\otimes$ denotes kronecker product) has not been determined. Some empirical observations on the accuracy of solutions of certain instances of (12) suggest that one factor influencing conditioning of (12) is the proximity of the spectrum of $F$ to the imaginary axis. To be more specific, suppose $F$ has an eigenvalue at $a \pm j b$ with $\left|\frac{b}{a}\right| \gg 1$ (typically $a<0$ is very small). If $\left|\frac{b}{a}\right|=0\left(10^{t}\right)$ we lose approximately $t$ digits of accuracy and we might expect a condition number for the solution of (12) to also be $0\left(10^{t}\right)$ in this situation.

There are some close connections between (12) and (1) (and the respective discrete-time versions) and we shall indicate some preliminary observations here. A perturbation analysis or the notion of a condition number for (1) is intimately related to the condition of an associated Lyapunov equation, namely one whose "F-matrix" approximates the closedloop matrix F-GX where $X$ solves (1). To illustrate, suppose $X=Y+E$ where $Y=Y^{T}$ may be interpreted as an approximation of $X$. Then

$$
\begin{aligned}
0 & =F^{T}(Y+E)+(Y+E) F-(Y+E) G(Y+E)+H \\
& \approx(F-G Y){ }^{T} E+E(F-G Y)+\left(F^{T} Y+Y F-Y G Y+H\right) \\
& =\hat{F}^{T} E+E \hat{F}+\hat{H}
\end{aligned}
$$

where we have neglected the second-order term EGE. Thus conditioning of (1) should be closely related to nearness of the closed-loop spectrum $(\sigma(F-G X))$ to the imaginary axis. Observations similar to these have been made elsewhere; see, for example, Bucy [31] where the problem is posed as one of structural stability. A condition number might, in some sense, be thought of as a quantitative measure of the degree of structural stability. 
Another factor involved in the conditioning of (1) relates to the assumptions of stabilizability of $(F, B)$ and detectability of $(C, F)$. For example, near-unstabilizability of $(F, B)$ in either a parametric sense or in a control energy sense (i.e., near-singular controllability Gramian) definitely causes (1) to become badly conditioned. Our experience has been that the ill-conditioning manifests itself in the algorithm by a badly conditioned $\mathrm{U}_{11}$.

Work related to the conditioning of (1) and (8) is under continuing investigation and will be the subject of another paper. Such analysis is, of course, independent of the particular algorithm used to solve (1) or (8), but is useful to understand how ill-conditioning can be expected to manifest itself in a given algorithm. 
5. Advantages of the Schur Vector Approach and Further General Remarks

\subsection{Advantages of the Schur Vector Approach}

The advantages of this algorithm over others using eigenvectors (such as Potter's approach [10] and its extensions) are obvious. Firstly, the reduction to RSF is an intermediate step in computing eigenvectors anyway (using the double Francis $\mathrm{QR}$ algorithm) so the Schur approach must, by definition, be faster usually by a factor of at least two. Secondly, and more importantly, this algorithm will not suffer as severely from the numerical hazards inherent in computing eigenvectors associated with multiple or near-multiple eigenvalues. The computation of eigenvectors is fraught with difficulties (see, e.g. [21] for a cogent discussion) and the eigenvectors themselves are simply not needed. All that is needed is a basis for the eigenspace spanned by the eigenvalues of $z$ with negative real parts (with an analogous statement for the discretetime case). As good a basis as is possible (in the presence of rounding error) for this subspace can be found from the Schur vectors comprising the matrix $\left(\begin{array}{c}\mathrm{U} \\ 11 \\ \mathrm{U}_{21}\end{array}\right)$, independently of individual eigenvalue multiplicities. The reader is strongly urged to consult [32] and [21] (especially pp. 609610) for further numerical details.

The fact that any basis for the stable eigenspace can be used to construct the Riccati equation solution has been noted by many people; see [12] or [3] among others. The main stumbling block with using the Schur vectors was theordering problem with the RSF but once that is handled satisfactorily the algorithm is easy. 
The Schur vector approach derives its desirable numerical properties from the underlying $Q R$-type process. To summarize: if you like the eigenvector approach for solving the algebraic Riccati equation you'll like the Schur vector approach at least twice as much.

Like the eigenvector approach, the schur vector approach has the advantage of producing the closed-loop eigenvalues (or whatever is appropriate to the particular application from which the Riccati equation arises) essentially for free. And finally, an important advantage of the Schur vector approach, in addition to its general reliability for engineering applications, is its speed in comparison with other methods. We have already mentioned the advantage, by definition, over previous eigenvector approaches but there is also generally an even more significant speed advantage over iterative methods. This advantage is particularly apparent in poorly conditioned problems and in cases in which the iterative method has a bad starting value. of course, it is impossible to make the comparison between a direct versus iterative method any more precise for general problems but we have found it not at all uncommon for an iterative method, such as straightforward Newton [14], to take ten to thirty times as long - if, indeed, there was convergence at all.

\subsection{Miscellaneous General Remarks}

\footnotetext{
Remark 1: There are, in general, as many as $\left.\left(\begin{array}{c}2 \mathrm{n} \\ \mathrm{n}\end{array}\right) \begin{array}{c}\text { solutions of an } \\ (2 \mathrm{n}\end{array}\right)$ $n$th order Riccati equation corresponding to as many as $\left(\begin{array}{l}2 n \\ n\end{array}\right)$ choices of $n$ of the $2 \mathrm{n}$ eigenvalues of $\mathrm{z}$. Any of these solutions may also be generated by the Schur approach, as for the eigenvector approach, by an appropriate reordering of the RSF. For most control and filtering applications we
} 
are interested in the unique nonnegative definite solution and have thus concentrated the exposition on that particular case.

Remark 2: One of the most complete sources for an eigenvector-oriented proof of Theorem 5 for the general case of multiple eigenvalues is Martensson [13]. But even a casual glance at that proof exposes the awkwardness of fussing with eigenvectors and principal vectors. The proof using Schur vectors is extremely clean and easy by comparison and neatly avoids any difficulties with multiple eigenvalues. This observation is but one instance of the more general observation that schur voctors can probably always replace principal vectors (or generalized eigenvectors) corresponding to multiple eigenvalues throughout linear control/systems theory. Principal vectors are not generally reliably computable in the presence of roundoff error anyway (see [21]) and a basis for an eigenspace - but not the particular one corresponding to the principal vectors is all that is normally needed. Use of Schur vectors will not only frequently provide cleaner proofs but is also numerically much more attractive.

Remark 3: As an alternative to the direct proofs provided in Sections 2 and 3 one could simply appeal to the proofs given for the eigenvector approach and note that the schur vectors are related to the eigenvectors by a nonsingular transformation. Specifically, with $Z, U$, and $S$ as before, let $v \in \mathbb{R}_{2 \mathrm{n}}^{2 \mathrm{n} 2 \mathrm{n}}$ put $\mathrm{z}$ in real Jordan form

$$
v^{-I} \mathrm{zV}=\left(\begin{array}{cc}
-\Lambda & 0 \\
0 & \Lambda
\end{array}\right)
$$

$\left(\mathbb{R}_{2 \mathrm{n}}^{2 \mathrm{n} \times 2 \mathrm{n}}\right.$ denotes the set of $2 \mathrm{n} \times 2 \mathrm{n}$ matrices or rank $2 \mathrm{n}$, i.e., invertible) 
where $-\Lambda$ is the real Jordan form of the eigenvalues of $z$ with negative real parts (analogous remarks apply as usual, for the discrete-time case). Furthermore, let $T \in \mathbb{R}_{n}^{\mathrm{nxn}}$ transform $S_{11}$ to the real Jordan form $-\Lambda$. Then

$$
z\left(\begin{array}{c}
v_{11} \\
v_{21}
\end{array}\right)=\left(\begin{array}{c}
v_{11} \\
v_{21}
\end{array}\right)(-\Lambda)
$$

and

$$
z\left(\begin{array}{c}
u_{11} \\
u_{21}
\end{array}\right)=\left(\begin{array}{c}
u_{11} \\
u_{21}
\end{array}\right) s_{11} .
$$

We thus have

$$
\begin{aligned}
\mathrm{z}\left(\begin{array}{c}
\mathrm{U}_{11} \\
\mathrm{U}_{21}
\end{array}\right) \mathrm{T} & =\left(\begin{array}{c}
\mathrm{U}_{11} \\
\mathrm{U}_{21}
\end{array}\right) \mathrm{TT}^{-1} \mathrm{~S}_{11} \mathrm{~T} \\
& =\left(\begin{array}{c}
\mathrm{U}_{11} \\
U_{21}
\end{array}\right) \mathrm{T}(-\Lambda)
\end{aligned}
$$

Since eigenvectors are unique up to nonzero scalar multiple we must have

$$
\left(\begin{array}{c}
\mathrm{U}_{11} \\
\mathrm{U}_{21}
\end{array}\right)_{\mathrm{T}}=\left(\begin{array}{c}
\mathrm{v}_{11} \\
\mathrm{v}_{21}
\end{array}\right) \mathrm{D}
$$

where $D$ is diagonal and invertible. Thus $\left(\begin{array}{c}U_{11} \\ U_{21}\end{array}\right)=\left(\begin{array}{c}V_{11} \\ V_{21}\end{array}\right) D^{-1}$ and since
$V_{21} V_{11}^{-1}$ solves (1), $U_{21} U_{11}^{-1}$ must also solve $(1)^{-1}$ since

$$
\mathrm{U}_{21} \mathrm{U}_{11}^{-1}=\mathrm{V}_{21} \mathrm{DT}^{-1}\left(\mathrm{~V}_{11} \mathrm{DT}^{-1}\right)^{-1}=\mathrm{V}_{21} \mathrm{~V}_{11}^{-1}
$$


However, we have chosen to provide self-contained proofs because of their simplicity and also because the proof in section 3 is not as widely seen as its continuous-time counterpart.

Remark 4: The same Schur vector approach employed in this paper can also be used instead of the eigenvector approach for the nonsymmetric matrix quadratic equation

$$
\mathrm{XEX}+\mathrm{FX}+\mathrm{XG}+\mathrm{H}=\mathrm{O}
$$

where $E \in \mathbb{R}^{m \times n} ; F \in \mathbb{R}^{n \times n}, G \in \mathbb{R}^{m \times m} ; H \in \mathbb{R}^{n \times m}$; and $X \in \mathbb{R}^{n \times m}$. In this case we work with the $(m+n) \times(m+n)$ matrix

$$
Z=\left(\begin{array}{cc}
-G & -E \\
H & F
\end{array}\right)
$$

and various solutions of (13) are determined by generating appropriate combinations of $\mathrm{m}$ eigenvalues of $\mathrm{z}$ along the diagonal of the RSF of $z$. The corresponding $m$ Schur vectors give the solution $x=U_{21} U_{11}^{-1}$ as before where $U_{11} \in \mathbb{R}^{\mathrm{mxm}}, U_{2 I} \in \mathbb{R}^{\mathrm{nxm}}$. The analogous remarks apply for the corresponding nonsymmetric "discrete-time equation". Proofs are essentially the same in both cases. Further details on the eigenvector approach can be found in [33], [34].

Remark 5: Special cases of the matrix quadratic equations such as (1), (8), or (13) include the Lyapunov equation (12) (or its discretetime counterpart $F^{T} X F-X+H=0$ ) and the sylvester equation

$$
\mathrm{FX}+\mathrm{XG}+\mathrm{H}=\mathrm{O}
$$

(or its discrete-time counterpart FXG $-\mathrm{X}+\mathrm{H}=0$ ). 
Thus setting an appropriate block of the $\mathrm{Z}$ matrix equal to 0 provides a method of solving such "linear equations" and, in fact, this method has even been proposed in the literature [35]. However, the approach probably has little to recommend it from a numerical point of view as compared to applying the Bartels-Stewart algorithm [39] and we mention it only in passing. 


\section{Examples}

In this section we give a few examples both to illustrate various points discussed previously and to provide some numerical results for comparison with other approaches. All computations were done at M.I.T. on an IBM 370/168 using FORTRAN H Extended (Opt. $=2$ ) and double precision arithmetic.

Example 1: The Schur vector approach is obviously not well-suited to hand computation - which partly explains its desirable numerical properties. However, to pacify a certain segment of the population a "hand example" is provided in complete detail. Consider the equation

$$
A^{T} X+X A-X B R^{-1} B^{T} X+Q=0
$$

which arises in a linear-quadratic optimal control context with

$$
A=\left(\begin{array}{ll}
0 & 1 \\
0 & 0
\end{array}\right), \quad B=\left(\begin{array}{l}
0 \\
1
\end{array}\right), \quad R=1, \quad Q=\left(\begin{array}{ll}
1 & 0 \\
0 & 2
\end{array}\right) .
$$

$\mathrm{Z}=\left|\begin{array}{cccc}0 & 1 & 0 & 0 \\ 0 & 0 & 0 & -1 \\ -1 & 0 & 0 & 0 \\ 0 & -2 & -1 & 0\end{array}\right|$

$$
U=\left|\begin{array}{rrrr}
\frac{1}{2} & -\frac{\sqrt{5}}{10} & -\frac{3 \sqrt{5}}{10} & \frac{1}{2} \\
-\frac{1}{2} & -\frac{\sqrt{5}}{10} & -\frac{3 \sqrt{5}}{10} & -\frac{1}{2} \\
\frac{1}{2} & -\frac{3 \sqrt{5}}{10} & \frac{\sqrt{5}}{10} & -\frac{1}{2} \\
-\frac{1}{2} & -\frac{3 \sqrt{5}}{10} & \frac{\sqrt{5}}{10} & \frac{1}{2}
\end{array}\right|
$$


is an orthogonal matrix which reduces $z$ to $\mathrm{RSF}$

$$
S=U^{\mathrm{T}} Z U=\left|\begin{array}{cccr}
-1 & 0 & 1 & -\frac{1}{2} \\
0 & -1 & -1 & 1 \\
0 & 0 & 1 & 0 \\
0 & 0 & 0 & 1
\end{array}\right| \text {. }
$$

Then the unique positive definite solution of (15) is given by the solution of the linear matrix equation

$$
\mathrm{xu}_{11}=\mathrm{U}_{21}
$$

or

$$
\left(\begin{array}{ll}
x_{11} & x_{12} \\
x_{12} & x_{22}
\end{array}\right)\left(\begin{array}{cc}
\frac{1}{2} & -\frac{\sqrt{5}}{10} \\
-\frac{1}{2} & -\frac{\sqrt{5}}{10}
\end{array}\right)=\left(\begin{array}{cc}
\frac{1}{2} & -\frac{3 \sqrt{5}}{10} \\
-\frac{1}{2} & -\frac{3 \sqrt{5}}{10}
\end{array}\right) .
$$

Thus $X=\left(\begin{array}{ll}2 & 1 \\ 1 & 2\end{array}\right)$ and it can quickly be checked that the spectrum of the "closed-10op matrix" $\left(A-B R^{-1} B^{T} X\right)=\left(\begin{array}{cc}0 & 1 \\ -1 & -2\end{array}\right)$ is $\{-1,-1\}$ as was evident from $\mathrm{S}_{11}$.

Example 2: For checking purposes consider the solution of (15) with the following uncontrollable but stabilizable, and unobservable but detectable data:

$$
A=\left(\begin{array}{cc}
4 & 3 \\
-\frac{9}{2} & -\frac{7}{2}
\end{array}\right), \quad B=\left(\begin{array}{c}
1 \\
-1
\end{array}\right), \quad R=1, \quad 2=\left(\begin{array}{ll}
9 & 6 \\
6 & 4
\end{array}\right) \text {. }
$$




$$
-35-
$$

The solution of (15) is $x=\left(\begin{array}{cc}9 c & 6 c \\ 6 c & 4 c\end{array}\right)$ where $c=1+\sqrt{2}$ and the closedloop spectrum is $\left\{-\frac{1}{2},-\sqrt{2}\right\}$. These values were all obtained correctly to at least 14 significant figures as were the values for the corresponding discrete-time problem

$$
A^{T} X A-X-A^{T} X B\left(R+B^{T} X B\right)^{-I_{B}}{ }^{T} X A+Q=0
$$

the solution of which is

$$
x=\left(\begin{array}{cc}
9 d & 6 d \\
6 d & 4 d
\end{array}\right)
$$

where $d=\frac{1+\sqrt{5}}{2}$ and the closed-loop spectrum is $\left\{-\frac{1}{2}, \frac{3-\sqrt{5}}{2}\right\}$.

Example 3: For further comparison purposes consider the discrete-time system of Example 6.15 in [36] where

$$
\begin{aligned}
& A=\left(\begin{array}{cc}
0.9512 & 0 \\
0 & 0.9048
\end{array}\right), \quad B=\left(\begin{array}{cc}
4.877 & 4.877 \\
-1.1895 & 3.569
\end{array}\right) . \\
& R=\left(\begin{array}{ll}
\frac{1}{3} & 0 \\
0 & 3
\end{array}\right), \quad Q=\left(\begin{array}{cc}
0.005 & 0 \\
0 & 0.02
\end{array}\right) .
\end{aligned}
$$

The solution of (16) is given by

$$
x=\left(\begin{array}{ll}
0.010459082320970 & 0.003224644477419 \\
0.003224644477419 & 0.050397741135643
\end{array}\right)
$$

and the feedback gain $\bar{F}=\left(R+B^{T} X B\right)^{-1}{ }_{B}{ }_{X A}$ is given by

$$
\bar{F}=\left(\begin{array}{lc}
0.071251660724426 & -0.070287376494153 \\
0.013569839235296 & 0.045479287667006
\end{array}\right)
$$


Note the typographical error in the $(1,2)$-element of $\bar{F}$ in [36]. The closed-loop eigenvalues are given by

$$
0.508333461684191 \text { and } 0.688069670988913
$$

These are definitely different from [36] but have the same sum. Our numbers do appear to be the correct ones.

Example 4: We now consider somewhat higher order Riccati equations arising from position and velocity control for a string of high-speed vehicles. The matrices are taken from a paper by Athans, Levine, and Levis [37]. For a string of $\mathrm{N}$ vehicles it is necessary to solve the Riccati equation

$$
A_{N}^{T} X_{N}+x_{N} A_{N}-x_{N} B_{N} R_{N}^{-1} B_{N}^{T} X_{N}+Q_{N}=0
$$

where all matrices are of order $\mathrm{n}=2 \mathrm{~N}-1$ and are given by

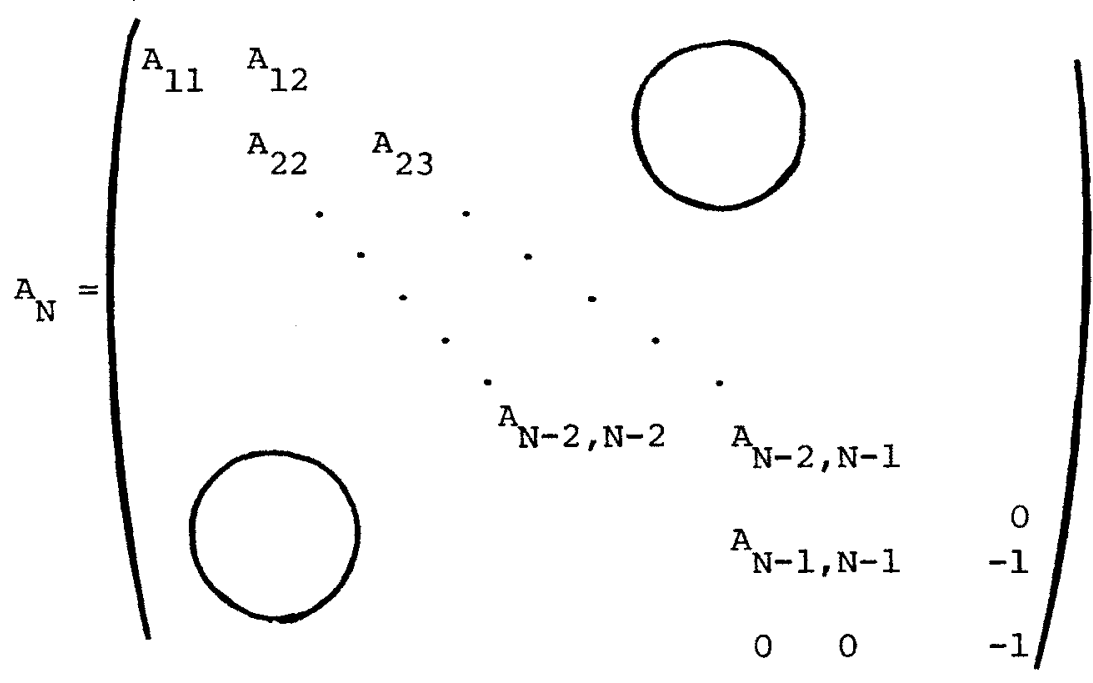

where $A_{k, k}=\left(\begin{array}{cc}-1 & 0 \\ 1 & 0\end{array}\right), \quad A_{k, k+1}=\left(\begin{array}{cc}0 & 0 \\ -1 & 0\end{array}\right)$ 
and $\mathrm{B}_{\mathrm{N}} \mathrm{R}_{\mathrm{N}}^{-1} \mathrm{~B}_{\mathrm{N}}^{\mathrm{T}}=\operatorname{diag}\{1,0,1,0, \ldots, 0,1\}$

$$
Q_{\mathrm{N}}=\operatorname{diag}\{0,10,0,10, \ldots, 10,0\}
$$

For the case of 5 vehicles we repeated the calculations presented in [37]. The correct values for $x$ rounded to six significant figures are:

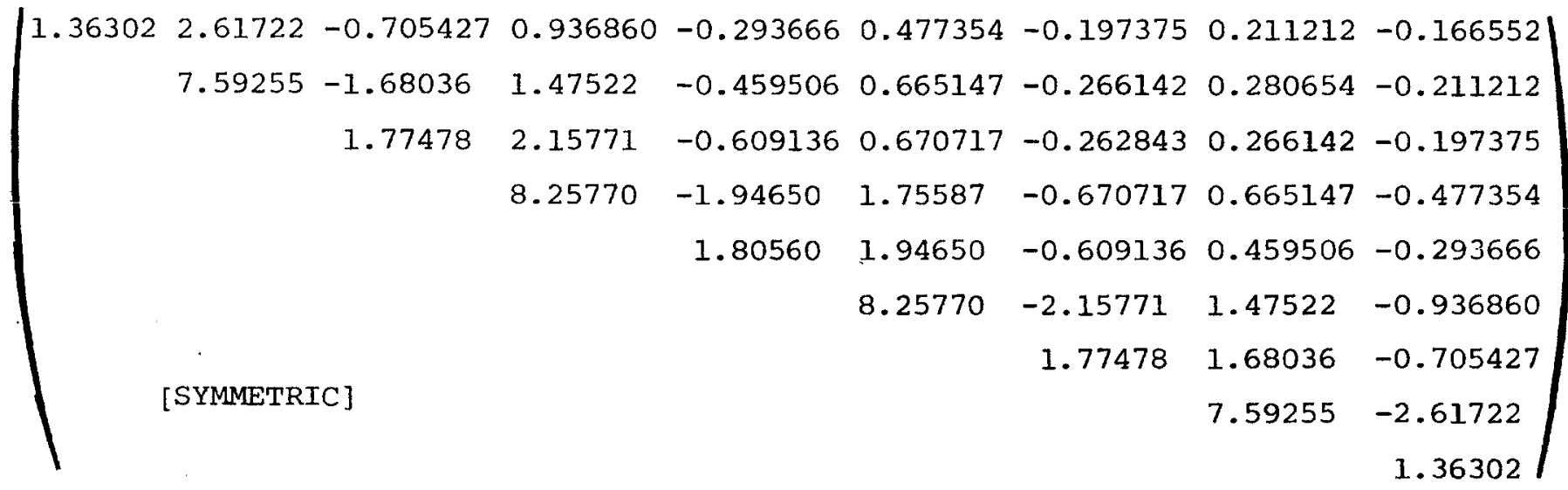

While 4 or 5 decimal places are published in [37], it can be seen that, surprisingly, only the first and sometimes the second were correct. Substitution of our full 16 decimal place solution into the Riccati equation gives a residual of norm on the order of $10^{-14}$ (consistent with a condition estimate of $U_{11}$ of 26.3 ) while the residual for the solution in [37] has a large norm on the ordex of $10^{-1}$. The closed-loop eigenvalues for the above problem (again rounded to six significant figures) are:

$$
\begin{aligned}
& -1.00000 \\
& -1.10779+0.852759 j \\
& -1.45215 \pm 1.26836 \quad j \\
& -1.67581 \mp 1.51932 \mathrm{j} \\
& -1.80486 \pm 1.66057 \mathrm{j}
\end{aligned}
$$

We also computed the Riccati solution and closed-loop eigenvalues for the cases of 10 and 20 vehicles. This involved the solutions of 19th and 39th order Riccati equations, respectively, and rather than 
reproduce all the numbers here we give only the first five and last five elements of the first row (or column) of $\mathrm{x}$ and the fastest and slowest closed-1oop modes. Again all values are rounded to just six significant figures; the complete numerical solutions are available from the author.

\begin{tabular}{|c|c|c|c|}
\hline $\begin{array}{c}\text { First row }(\mathrm{cc} \\
\text { Solution } \\
\mathrm{N}=10 \\
\mathrm{n}=19 \\
\end{array}$ & $\begin{array}{l}m n) \text { of Riccati } \\
\begin{aligned} N & =20 \\
n & =39\end{aligned}\end{array}$ & $\begin{array}{l}\text { Fastest and Slowest } \\
\qquad \begin{array}{r}N=10 \\
n=19\end{array}\end{array}$ & $\begin{array}{l}\text { Closed-Loop Modes } \\
\mathrm{N}=20 \\
\mathrm{n}=39\end{array}$ \\
\hline 1.40826 & 1.42021 & -1.83667 & -1.84459 \\
\hline 2.66762 & 2.68008 & $\pm 1.69509 \mathrm{j}$ & $\pm 1.70368 \mathrm{j}$ \\
\hline-0.658219 & -0.646127 & : & : \\
\hline 1.04031 & 1.06539 & -0.862954 & -0.662288 \\
\hline-0.242133 & -0.229761 & $\pm 0.494661 j$ & \\
\hline & & & \\
\hline-0.0515334 & -0.0123718 & & \\
\hline 0.103453 & 0.0250824 & & \\
\hline-0.0472086 & -0.0120915 & & \\
\hline 0.0504036 & 0.0124632 & & \\
\hline-0.0452352 & -0.0119545 & & \\
\hline
\end{tabular}

The closed-loop eigenvalues for the case of, say, 10 vehicles interlace and include, as a subset, those of 5 vehicles. Similarly, those for 20 vehicles interlace and include, as a subset, those of 10 (and hence 5) vehicles. It appears evident that both the elements of the Riccati solution and the closed-loop eigenvalues are converging to values in some finite region.

Example 5: This example involves circulant matrices. We wish to solve (15) with 


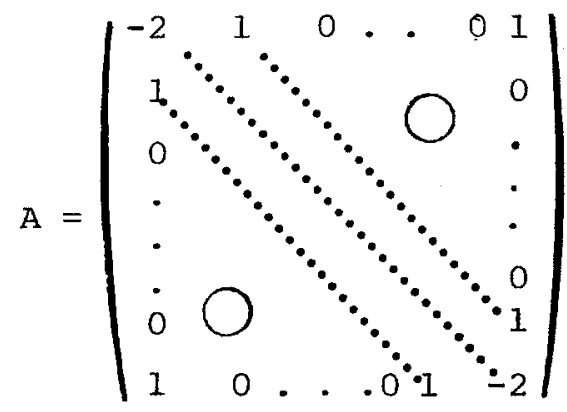

and $\mathrm{BR}^{-1} \mathrm{~B}^{\mathrm{T}}=I, Q=I$. The matrices $A, \mathrm{BR}^{-I_{B} \mathrm{~T}}, \mathrm{Q}$ are all circulant so the Riccati solution $\mathrm{X} \in \mathbb{R}^{\mathrm{nxn}}$ is known to be circulant of the form

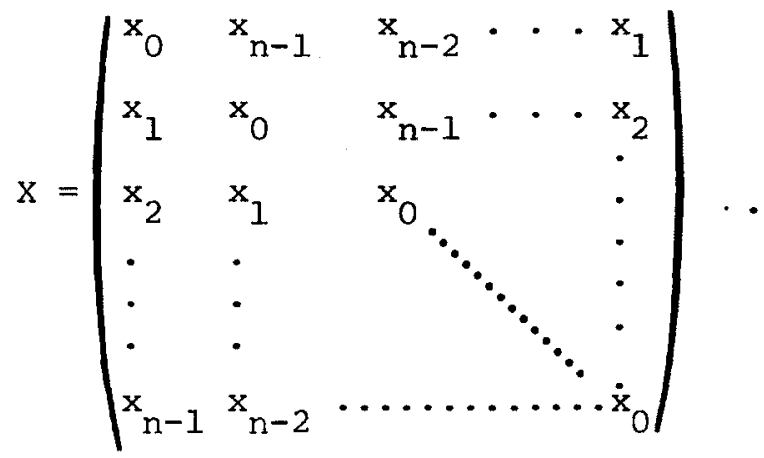

In fact, there is a simple transformation which "diagonalizes" the Riccati equation and allows the solution of (15) to be recovered via the solution of $\mathrm{n}$ scalar quadratic equations and an inverse discrete Fourier transform. The details of this procedure and related analysis of circulant systems can be found in the work of wall [38]. For this example, we have $n=64$ and the $x_{i}$ are given by

$x_{i}=\frac{1}{64} \sum_{k=0}^{63}\left\{-2+2 \cos \left(\frac{2 \pi k}{64}\right)+\sqrt{5-4 \cos \left(\frac{2 \pi k}{64}\right)+4 \cos ^{2}\left(\frac{2 \pi k}{64}\right)}\right\} \omega_{64}^{i k}$

where $\omega_{64}$ is a $64-$ th root of unity. The solution was computed by the Schur vector approach and checked by means of the circulant analysis 
of Wall. Our computed Riccati solution had at least 13 significant figures. For reference purposes we list

$$
\begin{aligned}
& x_{11}=0.37884325313566 \\
& x_{12}=0.18581947375535 \\
& \cdot \\
& \cdot \\
& x_{44}=0.37884325313567 \\
& x_{45}=0.18581947375536 \\
& \cdot \\
& \cdot
\end{aligned}
$$

The closed-loop eigenvalues are all real and are arranged as follows: $-4.1231056256177$

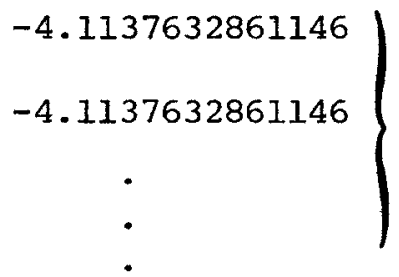

$-0.99999999999991$

This $64^{\text {th }}$ order example required approximately $50 \mathrm{sec}$. of CPU time on the $370 / 168$ at M.I.T. and approximately $34 \mathrm{sec}$. on the $370 / 165$ at the University of Toronto - both using FORTRAN H Extended (Opt. $=2$ ), double precision.

Example 6: This example is one which would be expected to cause problems on physical grounds and which appears to give rise to an "ill-conditioned Riccati equation". Consider the solution of (15) with 


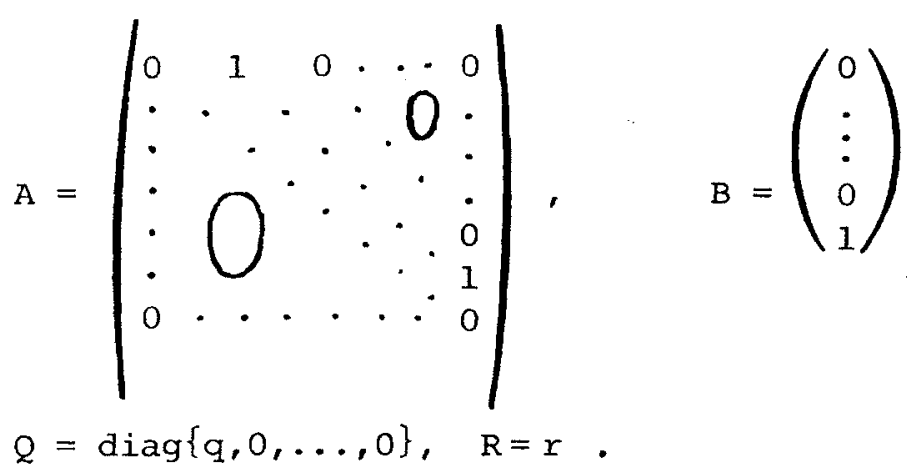

Here we have a system of $\mathrm{n}$ integrators connected in series. It is desired to apply a feedback controller to the $n^{\text {th }}$ system (which is to be integrated $\mathrm{n}$ times) so as to achieve overall asymptotic stability. Only deviations of $\mathrm{x}_{1}$ (the $\mathrm{n}$ th integral of the constant system) from 0 are penalized. The controllability Gramian

$$
w_{t}=\int_{0}^{t} e^{s A_{B B}{ }^{T} e^{s A^{T}}} d s \text {, }
$$

while positive definite for all $t>0$, becomes more nearly singular as $n$ increases. The system is "hard to control" in the sense of requiring a large amount of control energy (as measured by $\left\|w_{t}^{-1}\right\|$ ). The closed-loop eigenvalues are easily seen to be the roots of

$$
\lambda^{2 n}+(-1)^{n} \frac{q}{r}=0
$$

with negative real parts. These eigenvalues lie in a classic Butterworth pattern. It can also be easily verified that

$$
\begin{aligned}
x_{\ln } & =\sqrt{\frac{q}{r}} \\
& =\text { product of the closed-loop eigenvalues. }
\end{aligned}
$$


We attempted the solution of (15) with the above matrices and $q=r=1$. While the closed-loop eigenvalues were determined quite accurately as expected (approximately 14 decimal places using IBM double precision), the Riccati solution was increasingly less accurate as $\mathrm{n}$ increased due to the increasingly ill-conditioned nature of $U_{11}$. For example, for $\mathrm{n}=21$ there was already a loss of 10 digits of accuracy (consistent with a condition estimate of $\mathrm{O}\left(10^{10}\right.$ ) for $\left.\mathrm{U}_{11}\right)$ in $\mathrm{x}_{1 \mathrm{n}}(=1)$. Other computed elements of $\mathrm{x}$ were as large as $O\left(10^{9}\right)$ in magnitude.

Repeating the calculations with $q=10^{4}, r=1$ there was a loss of approximately 12 digits of accuracy in $x_{1 n}(=100)$ for $n=21$. In this case other elements of $\mathrm{x}$ were as large as $0\left(10^{11}\right)$ in magnitude. Again, the closedloop eigenvalues were determined very accurately.

Our attempts to get Newton's method to converge on the above problem were unsuccessful.

Obviously, there is more that can be said analytically about this problem. Our interest here has been only to highlight some of the numerical difficulties. 


\section{Concluding Remarks}

We have discussed in considerable detail a new algorithm for solving algebraic Riccati equations. A number of numerical issues have been addressed and various examples given. The method is apparently quite numerically stable and performs reliably on systems with dense matrices of up to order 100 or so, storage being the main limiting factor.

For some reason, numerical analysts have never really studied algebraic Riccati equations. The algorithm presented here can undoubtedly be refined considerably from a numerical point of view but it nonetheless represents an immense improvement over algorithms heretofore proposed.

Some topics of continuing research in this area will include:

(i) conditioning of Riccati equations,

(ii) use of software to sort blocks of the RSF diagonal into just the two appropriate groups rather than within the two groups as well,

(iii) making numerically viable the use of symplectic transformations such as in [17] to reduce the Hamiltonian or symplectic matrix $\mathrm{z}$ to a convenient canonical form.

Each of these topics is of research interest in its own right in addition to the application to Riccati equations. 


\section{References}

[1] Wonham, W.M., On a Matrix Riccati Equation of Stochastic Control, SIAM J. Contr., 6(1968), 681-697.

[2] Reid, W.T., Riccati Differential Equations, Academic Press, New York, 1972.

[3] Willems, J.C., Least Squares Stationary Optimal Control and the Algebraic Riccati Equation, IEEE Trans. Aut. Contr., AC-16(1971), $621-634$.

[4] Silverman, L.M., Discrete Riccati Equations: Alternative Algorithms, Asymptotic Properties, and System Theory Interpretations, in Advances in Control Systems, Vol. 12, (Leondes, Ed.), Academic Press, New York, 1976, pp. 313-386.

[5] Lainiotis, D.G., Partitioned Riccati Solutions and Integration-Free Doubling Algorithms, IEEE Trans. Auto. Contr., AC-21 (1976), 677-689.

[6] Rodriguez-Canabal, J., The Geometry of the Riccati Equation, Stochastics, 1(1973), 129-149.

[7] Pachter, M., and T.E. Bullock, Ordering and Stability Properties of the Riccati Equation, Na. Res. Inst. for Math. Sci. Report, WISK 264, Pretoria, June 1977.

[8] Von Escherich, G., Die Zweite Variation der Einfachen Integrale, Wiener Sitzungsberichte, 8(1898), 1191-1250.

[9] MacFarlane, A.G.J., An Eigenvector Solution of the Optimal Linear Regulator Problem, J. Electron. Contr., 14(1963), 643-654.

[10] Potter, J.E., Matrix Quadratic Solutions, SIAM J. Appl. Math., 14(1966), 496-501.

[11] Vaughn, D.R., A Nonrecursive Algebraic Solution for the Discrete Riccati Equation, IEEE Trans. Auto. Contr., AC-15(1970), 597-599.

[12] Fath, A.F., Computational Aspects of the Linear Optimal Regulator Problem, IEEE Trans. Auto. Contr., AC-14(1969), 547-550.

[13] Mártensson, K., New Approaches to the Numerical Solution of optimal Control Problems, Lund Institute of Technol., Divis. of Auto. Contr., Report No. 7206, Lund, Sweden, Mar. 1972.

[14] Kleinman, D.L., On An Iterative Technique for Riccati Equation Computations, IEEE Trans. Auto. Contr., AC-13(1968), 114-115. 
[15] Farrar, F.A., and R.C. DiPietro, Comparative Evaluation of Numerical Methods for Solving the Algebraic Matrix Riccati Equation, United Technologies Research Center Report No. R76-140268-1, East Hartford, CT, Dec. 1976.

[16] Hewer, G.A., and G. Nazaroff, A Survey of Numerical Methods for the Solution of Algebraic Riccati Equations, Naval Weapons Center Report, China Lake, CA.

[17] Laub, A.J., and K.R. Meyer, Canonical Forms for Hamiltonian and Symplectic Matrices, Celestial Mechanics, 9(1974), 213-238.

[18] Laub, A.J., Canonical Forms for $\sigma$-Symplectic Matrices, M.S. Thesis, School of Mathematics, Univ. of Minnesota, Dec. 1972.

[19] Stewart, G.W., Introduction to Matrix Computations, Academic Press, New York, 1973.

[20] Murnaghan, F.D., and A. Wintner, A Canonical Form for Real Matrices Under Orthogonal Transformations, Proc. Na. Acad. Sci., 17(1931), $417-420$.

[21] Golub, G.H., and J.H. Wilkinson, Ill-Conditioned Eigensystems and the Computation of the Jordan Canonical Form, SIAM Rev., 18(1976), 578-619.

[22] Gantmacher, F.R., The Theory of Matrices, Chelsea, New York, 1959.

[23] Dorato, P., and A. Levis, Optimal Linear Regulators: The DiscreteTime Case, IEEE Trans. Auto. Contr., AC-16(1971), 613-620.

[24] Albert, A., Conditions for Positive and Nonnegative Definiteness in Terms of Pseudoinverses, SIAM J. Appl. Math., 17(1969), 434-440.

[25] Penrose, R., A Generalized Inverse for Matrices, Proc. Cambr. Phil. Soc., 51(1955), 406-413.

[26] Stewart, G.W., HQR3 and EXCHNG: Fortran Subroutines for Calculating and Ordering the Eigenvalues of a Real Upper Hessenberg Matrix, ACM Trans. Math. Software, 2(1976), 275-280.

[27] Smith, B.T., et.al., Matrix Eigensystems Routines -- EISPACK Guide, Second Edition, Lect. Notes in Comp. Sci., Vol. 6, Springer-Verlag, New York, 1976.

[28] Forsythe, G.E., M.A. Malcolm, and C.B. Moler, Computer Methods for Mathematical Computations, Prentice-Hall, Englewood Cliffs, NJ, 1977. 
[29] Dongarra, J.J., J.R. Bunch, C.B. Moler, and G.W. Stewart, Preliminary LINPACK User's Guide, LINPACK Working Note \#9, Argonne National Laboratory, Appl. Math. Div., TM-313, Aug. 1977.

[30] Parlett, B.N., and C. Reinsch, Balancing a Matrix for Calculation of Eigenvalues and Eigenvectors, Numer. Math., 13(1969), 296-304.

[31] Bucy, R.S., Structural Stability for the Riccati Equation, SIAM J. Contr., 13(1975), 749-753.

[32] Wilkinson, J.H., The Algebraic Eigenvalue Problem, Oxford University Press, London, 1965.

[33] Coppel, W.A., Matrix Quadratic Equations, Bull. Austral. Math. Soc., $10(1974), 377-401$.

[34] Meyer, H.-B., The Matrix Equation AZ+B-ZCZ-ZD = 0, SIAM J. Appl. Math., 30(1976), 136-142.

[35] Bar-Ness, Y., and G. Langholz, The Solution of the Matrix Equation $\mathrm{XC}-\mathrm{BX}=\mathrm{D}$ as an Eigenvalue Problem, Int. J. Sys. Sci., 8(1977), 385392 .

[36] Kwakernaak, H., and R. Sivan, Linear Optimal Control Systems, Wiley, New York, 1972.

[37] Athans, M., W.S. Levine, and A. Levis, A System for the Optimal and Suboptimal Position and Velocity Control for a string of High-Speed Vehicles, Proc. 5th International Analogue Computation Meetings, Lausanne, Switzerland, Sept. 1967.

[38] Wall, J.E., Control and Estimation for Large-Scale Systems Having Spatial Symmetry, Ph.D. Thesis, M.I.T., Aug. 1978; Electronic Systems Lab. Rept. ESL-TH-842.

[39] Bartels, R.H., and G.W. Stewart, Solution of the Matrix Equation $\mathrm{AX}+\mathrm{XB}=\mathrm{C}$, Comm. $\mathrm{ACM}, 15(1972), 820-826$. 


\section{APPENDIX 1}

We outline here how to set up the "symplectic approach" when the matrix $F$ in

$$
F^{T} X F-X-F^{T} X G_{I}\left(G_{2}+G_{1}^{T} X G_{1}\right)^{-1} G_{1}^{T} X F+H=0
$$

is singular. All other assumptions and notation of section 3 will

be the same.

Letting $x_{k}$ denote the state at time $t_{k}$ and $\lambda_{k}$ the corresponding adjoint vector, recall the Hamiltonian difference equations arising from the discrete maximum principle:

$$
\left(\begin{array}{ll}
I & G \\
0 & F
\end{array}\right)\left(\begin{array}{l}
x_{k+1} \\
\lambda_{k+1}
\end{array}\right)=\left(\begin{array}{cc}
F & 0 \\
-H & I
\end{array}\right)\left(\begin{array}{l}
x_{k} \\
\lambda_{k}
\end{array}\right) \text {. }
$$

Note that if $F$ were invertible we could work with the symplectic matrix

$$
\left(\begin{array}{ll}
I & G \\
O & F^{T}
\end{array}\right)^{-1}\left(\begin{array}{cc}
F & 0 \\
-H & I
\end{array}\right)=\left(\begin{array}{cc}
F+G F^{-T H} & -G F^{-T} \\
-F^{-T} & F^{-T}
\end{array}\right)
$$

which is just (9). Here, instead, we shall be concerned with a "symplectic generalized eigenvalue problem"

$$
\mathbf{L z}=\lambda \mathbf{M z}
$$

with
$L=\left(\begin{array}{cc}F & 0 \\ -H & I\end{array}\right)$
$M=\left(\begin{array}{cc}I & G \\ 0 & F\end{array}\right)$ 
and symplectic in the sense that if $\lambda \neq 0$ is a generalized eigenvalue then $\frac{1}{\lambda}$ is a generalized eigenvalue. In fact, $L$ and $M$ are characterized by the property that

$$
\mathrm{LJL}^{\mathrm{T}}=\mathrm{MJM}^{\mathrm{T}} \text { where } J=\left(\begin{array}{cc}
0 & \mathrm{I} \\
-\mathrm{I} & 0
\end{array}\right) \text {. }
$$

In our specific situation $L J L^{T}=M^{T} M^{T}=\left(\begin{array}{cc}0 & F \\ & \\ -F^{T} & 0\end{array}\right)$.

There is even more "reciprocal symmetry" in the problem. With F singular there must be least one generalized eigenvalue at 0 and to each such generailized eigenvalue there corresponds its reciprocal at $\infty$. The generalized eigenvalues can then be arranged in two groups of $\mathrm{n}$ as before:

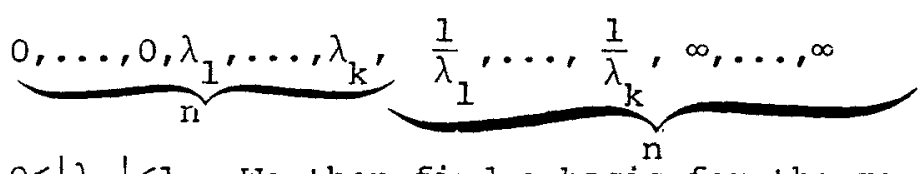

with $0<\left|\lambda_{i}\right|<1$. We then find a basis for the generalized eigenspace corresponding to $0, \ldots, 0, \lambda_{1}, \ldots, \lambda_{k}$ and proceed essentially as before. The details are omitted here as they are the subject of a forthcoming paper with T. Pappas. 


\section{APPENDIX 2}

In this appendix we provide FORTRAN source listings for one possible implementation of the schur vector approach described in the paper. Subroutines for solving both the continuous-time algebraic Riccati equation (1) [RICCND] and the discrete-time algebraic Riccati equation (8) [RICDSD] are given. The subroutine names are derived from the following nomenclature convention for a family of subroutines to solve Riccati and various other matrix equations:

subroutine name: XXXYYZ

where

$$
\begin{aligned}
& \mathrm{XXX}= \begin{cases}\text { RIC } & \text { Riccati equation } \\
\text { LYP } & \text { Iyapunov equation } \\
\text { SYL } & \text { SYlvester equation }\end{cases} \\
& \mathrm{YY}= \begin{cases}\mathrm{CN} & \text { continuous-time version } \\
\mathrm{DS} & \text { discrete-time version }\end{cases} \\
& \mathrm{Z}= \begin{cases}\mathrm{S} & \text { single (short) precision version } \\
\mathrm{D} & \text { double (Iong) precision version }\end{cases}
\end{aligned}
$$

Subroutine RICCND calls or further requires the following additional subroutines :

BALANC, BALBAK, DDCOMP, DSOLVE, EXCHNG, HQR3, MLINEQ, ORTHES, ORTRAN, QRSTEP, SPLIT

Subroutine RICDSD requires each of the 11 subroutines above as well as the two additional subroutines MULWOA, MULWOB. 
All the additional subroutines required have also been listed here with the exception of BALANC, BALBAK, ORTHES, and ORTRAN which are available in EISPACK [27].

These subroutines are being used in the environment described in Section 6 as part of a package called LQGPACK. This package is a preliminary version of a set of subroutines being developed at M.I.T.'s Laboratory for Information and Decision Systems to solve linear-quadraticGaussian control and estimation problems. The package has also been run in a single precision version on a CDC 6600. However, at this time we make no claims of portability of the code to other machines. The code listed here is solely for illustrative purposes.

Finally, we add two additional technical notes:

NOTE 1: A fairly reliable estimate of the condition number of $U_{11}$ with respect to inversion is returned by RICCND or RICDSD in WORK (1).

NOTE 2: The subroutine HQR3 contains a small error which can occasionally cause RICCND or RICDSD to give erroneous or misleading information. The trouble arises when ORTHES produces an upper Hessenberg form with a zero on the first subdiagonal. HQR3 then correctly orders the resulting RSF both above and below that zero element but not necessarily globally. In practice this almost never happens and it has only ever been observed for certain low-order examples with all coefficient matrices diagonal. This error in HQR3 can and will be corrected. In the interim, the error can either be ignored (a safe strategy for virtually all "real problems") or temporarily patched by the following scheme. 
Let $a_{i+1, i}$ be a zero element of the upper Hessenberg matrix $A$ (the output of ORTHES). Then before HQR3 is called, $a_{i+1}, i$ should be replaced by $\epsilon \cdot\left(\left|a_{i, i}\right|+\left|a_{i+1, i+1}\right|\right)$ where $e$ is the machine precision (EPS) defined by

$$
e=\min _{\delta}\{\delta: f \ell(1+|\delta|) \neq 1\}
$$

$(f \ell(\cdot)$ denotes floating point operation).

The source listings now follow. 
C

c

C

C

C

c

C

C

C

C

C

C

C

C

C

C

$c$

C

C

C

C

C

c

C

C

C

C

C

C

C

C

c

C

C

C

C

C

C

C

C

C

C

$c$

C
SUBEOUTINE RICCND (NZ,NF, NG,NH,N,NN,Z,W, F, G, H,ER, EI, BORK,

**** PAIRAETERS:

INTEG $\mathrm{TR} \quad \mathrm{NZ}, \mathrm{NF}, \mathrm{NG}, \mathrm{NH}, \mathrm{N}, \mathrm{NN}, \operatorname{ITYPE}(\mathrm{NN}), I P V L$ (NN),IPVS (N)

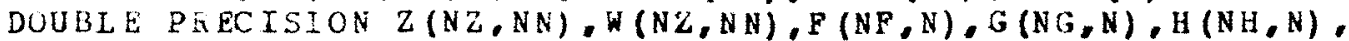
$+$ $E I(N N), E I(N N), W C R K(N), S C A L E(N N)$

****LOCAL VAHIABLES:

IATEGEE I, J,LOW, IGH, NLOW, NUP

DUUBLE PRECISION EPS, EPSP1, ZNOK , T, ALPHA,COND

* * * FUNCTICNS:

DOUBLE PRECISICN DABS, DSQRT

*****jubROUTtNeS CALLZD:

BALANC, BALBAK, HQE3, MLINEQ, OETHES, ORTRAN

$::::::::::::::::::::::::::::::::::::::::::::::::::::::::::::::::::$ :RIC00190

*****ORPOSE:

THIS SUBAOUTINL SOLVES THE CONTINUOUS-TIME

ALGEBRAIC MATEIX FICCATI EQUATICN

$$
F^{T} * X+X * F-X * G * X+H=0
$$

BY LAUB'S VARIANT OF WHE HAMILTONIAN-EIGENVECTOK APPROACH.

*****paraMeTín DESCEIPTION:

ON INPUT:

$$
N Z, N F, N G, N H
$$

N

NN

F

G. H

ON OUTPUT:

$\mathrm{H}$

$\mathrm{LR}, \mathbb{E} \mathrm{I}$
ROW DIMENSIUNS OF THE ARRAYS CONTAINING

$\mathrm{Z}$ (AND W), F, G, AND H, RESPECTIVELY, AS DECLALED IN THE CALLING PFOGRAM DIAENSION ST ATEMENT;

ORDER OF THE MATRICES F,G,H:

$=2 * N=$ ORDER OF THE INTERNALLY GENERATED MATKICES Z ANDW;

AN $N X N$ (REAL) MATEIX;

$N X N$ SYMMETRIC, NONNEGATIVE DEFINITE (REAL) УATRICES.
RIC 00010

RICO0020

RIC 00030

RIC 00040

RIC00050

RIC00060

\&IC00070

EIC 00080

RI C00090

R IC 00100

RICO0110

RIC 00120

RICO0 130

RIC 00140

RICO0150

RICO0160

RICOO 170

RICO0180

R ICOO200

RIC00210

RI C00220

RIC 00230

RICOO240

RIC 00250

RICOO 260

RIC00270

RIC00280

R IC 00290

RIC00300

RICO0310

RIC 00320

RIC 00330

EICO0 340

RIC00350

RIC00360

RI CO0 370

RIC 00380

RICO0 390

RIC 00400

RICOO410

RIC00420

RICOO430

RIC00440

RIC 00450

RICO0460

RIC 00470

RIC00480

AN $N$ X ARRAY CONTAINING THE UNIQOE POSTTIVE (OR NONNEGATIVE) DEFINITE SOLUTION OF THE FICCATI EQUATION;

RIC 00490

RIC 00500

RIC 00510

RIC 00520

RLAL SCRATCH VECTORS OF LENGTH $2 * N$; ON OUTPOT ( $E R(I), E I(I)), I=1, N$ CONTAIN THE REAL AND IMAGINARY DARTS, RESPECTIVELY, OF THE N
RIC00530

RIC 00540

RIC00550 
$E P S=1.0 D O$

WORK, SCALE

CLOSED LCOP EIGENVALUES (I.E.. THE SPECTEUM OF $F-G * X)$;

$2, w$

$2 * N \times 2 * N$ REAL SCRATCH ARRAYS USED FOR COMPOTATIONS INVOLVING THE HAUILTONIAN MATRIX ASSOCIATBD WITH THE RICCATI EQUATION;

REAL SCKATCH VECTORS OF LENGTHS $N, 2 * N$, EESPECTIVELY; ON OUTPUT, WORK (1) CONTAINS A CONDITION NOMBER ESTIMATE FOR THE FINAL NTH ORDER LINEAR MATRIX EQUATION SOLVED;

ITYPE, IPVL, IPVS INTEgER SCRATCH VECTORS OF LENGTHS $2 * N, 2 * N$, N. RESPECTIVELY.

\footnotetext{
***NOTE:
}

AL

IN THE CALL.***

*****ALGOEITHM NOTES:

IT IS ASSUMED THAT G AND H ARE NONNEgATIVE DEFINITE AND THAT (F, B) RIC00750

IS STABILIZABLE AND (C,F) IS DETECTABLE RHEBE $B * B^{T}=G$

$T=H \quad$ (C) OP FULL

(B OF PULL BANK = RANK (G)) AND $C * C=$ H (C OP FULL

RANK = RANK (H)) IN WHICH CASE THE SOLUTION (BETURNED IN THE

ARRAY H) IS ONIQUE AND NONNRGATIVE DEFINITE.

*****HISTORY:

WRITTEN BY ALA J. LAUB (ELEC. SYS. LAB., M.I.T.. RM. 35-331. CAMBRI DGE, MA 02139, PH .: (617) - 253-2125), SEPTEMBER 1977. MOST RECENT VERSION: SEP. 15, 1978.

$\ldots \ldots$

EPS IS AN I NTERNALLY GENERATED MACHINE DEPENDENT PARAMETEB SPECI FY ING THE RELATIVE PRECISION OF FLOATING POINT ARITHAETIC. FOB EXAMPLE, EPS $=16.000 *(-13)$ FOR DOUBLE PRECISION ARITHAETIC ON IB S $360 / 5370$.

c

c

$E P S=2.0 D O * E P S$

C

\section{SET UP HAMILTONIAN MATRIX}

DO $20 \mathrm{~J}=1, \mathrm{~N}$

$$
\text { DO } \begin{array}{rl}
10 & I=1, N \\
& \mathrm{Z}(I, J)=F(I, J)
\end{array}
$$

$Z(A+I, J)=-H(I, J)$

$Z(I, N+J)=-G(I, J)$

CONTINUE

$Z(N+I, N+J)=-F(J, I)$

CONTINUE

RIC 00560

RIC 00570

RIC 00580

RIC 00590

RIC00600

RIC 00610

RIC00620

RIC 00630

RIC00640

BIC 00650

RI C00660

RIC 00670

RI C00680

RIC00690

RIC00700

BIC00710

RIC00720

RIC00730

RIC00740

RIC 00760

RIC00770

RIC 00780

RIC00790

B IC 00800

RIC008 10

RIC 00820

RIC00830

BIC00840

RIC00850

RIC00860

RIC00870

: R IC 00880

RIC00890

RIC00900

BIC00910

BIC 00920

RIC00930

BIC00940

RIC 00950

RIC00960

BIC00970

RIC00980

RIC00990

RIC 01000

RIC0 1010

RIC01020

RIC0 1030

RIC01040

RIC0 1050

RIC01060

RIC0 1070

RIC01080

RIC0 1090

RIC01100 


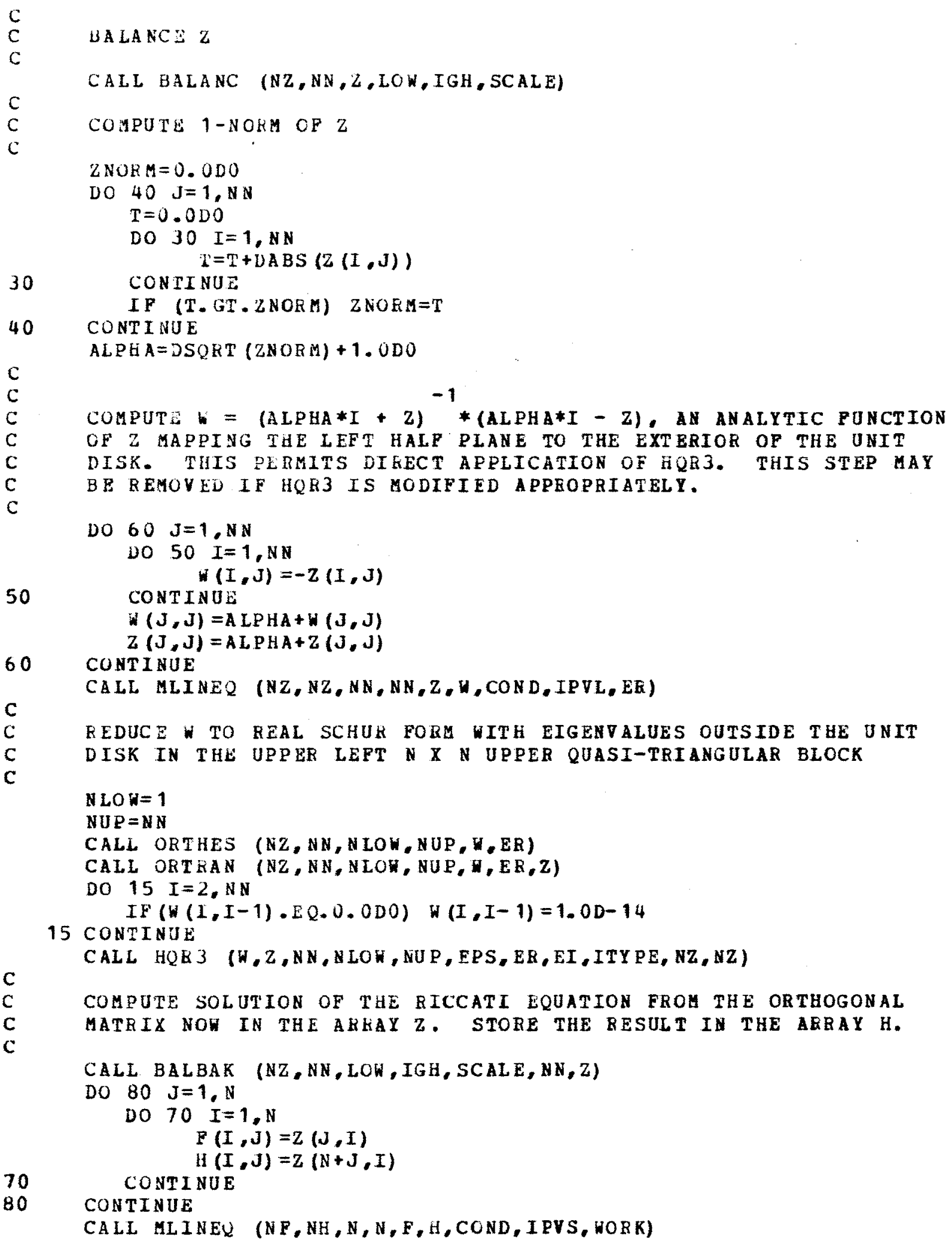

R IC 01110 RICO 1120 RIC01130 RIC 01140 RICO1150 RICO 1160 RICO 1170 RIC 01180 RICO 1190 RIC01200 RICO 1210 RIC01220 RIC 01230 RICO 1240 RIC 01250 RICO 1260 RIC 01270 RICO 1280 RIC 01290 RICO 1300 RIC01310 RICO1320 RIC01330 RIC0 1340 BICO 1350 RIC 01360 RIC0 1370 RIC 01380 RICO 1390 RIC 01400 RICO 1410 RICO1420 RICO 1430 RIC01440 RICO 1450 RICO 1460 RIC 01470 RICO 1480 RIC 01490 RICO 1500 RIC01510 RICO1520 RIC01530 RICO1540 RICO 1550 BIC01560 RICO 1570 RIC 01580 RICO 1590 RIC01600 RICO 1610 RIC01620 RICO 1630 RICO 1640 RIC 01650 


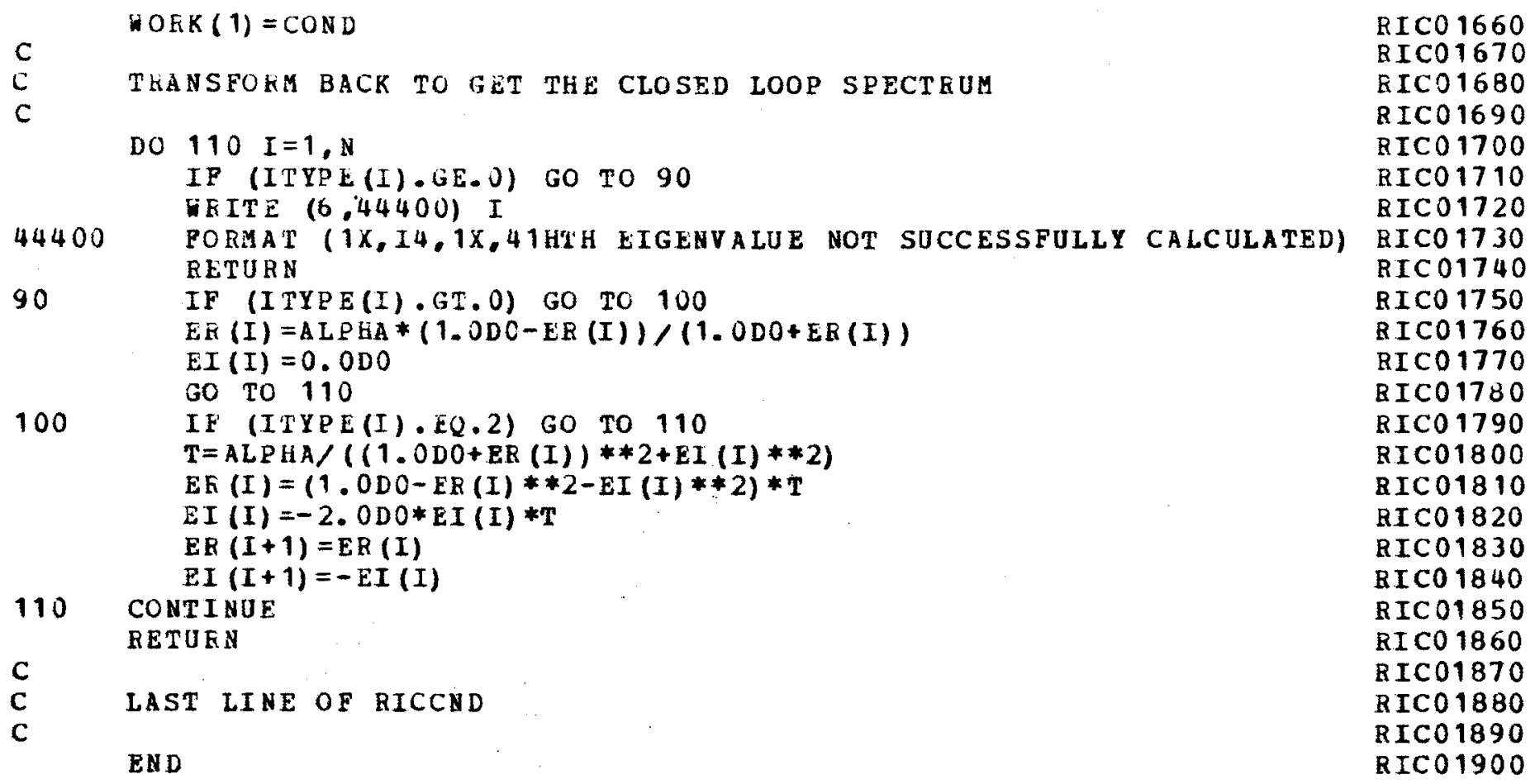


SUBSEUTINE

$\mathrm{C}$

$c$

C

C

C

C

C

C

C

C

C

C

C

C

C

c

C

C

C

*****2ARAMETES:

$1 N \mathrm{TEGER} N Z, N F, N G, N H, N, N N, \operatorname{ITYPE}(N N), \operatorname{IPVT}(\mathrm{N})$

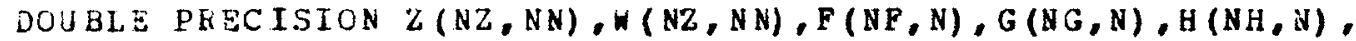

$+$ $E K(N N), E I(N N), H C R K(N), \operatorname{SCALE}(N N)$

**** LOCAL VARIABLES:

INTEGER I, J,K, LOW, IGH, NLOW, NUP

DUUBLE PEECISION EPS, EPSP1, COND, CONDP 1

*****SUBROUTINES CALLED:

BALANC, BALBAK, DDCOMP, DSOLVE,HQR 3, MLINEQ, UUL WOA, MULWOB, ORTHES,ORTRAN

$\because \ldots \ldots \ldots \ldots \ldots: \ldots: \ldots$

*****PUKPOSE:

THIS DOUBLE PEECISION SUBEOUTINE SOLVES THE DISCBETE-TIME ALGEBRAIC MATRIX KICCATI EQUATION

$$
X=F^{T} * X * F-F^{T} * X * G 1 *\left(\left(G 2+G 1^{T} * X * G 1\right)^{-1}\right) * G 1^{T} * X * F+H
$$

BY LAUB 'S VAEIANT OF THE HAMILTONIAN-EIGENVECTOR APPROACH.

THE MATKIX F IS ASSUMED TO BE NONSINGULAR AND THE MATRICES GI AND G2 ARE ASSUMED TO BE COMBINED INTO THE SQUAEE ARRAY G AS POLLONS:

$$
G=G 1 * G 2^{-1} * G 1^{T}
$$

*****PARAMETER DESCKIPTION:

ON INPUT:

$$
N Z, N E, N G, N H
$$

$\mathbb{N}$

N N

$\mathbf{F}$

G. B

UN OUTPUT:

H
ROW DIMENSIONS OF THE ARRAYS CONTAINING Z (AND W),F,G, AND H, BESPECTIVELY, AS DECIAEED IN THE CALIING PROGRAM DIMENSION STATEMENT;

OEDEE OF THE VATRICES P, G,H:

$=2 * N=$ ORDER OF THE INTERNALIY GENERATED MATRICES Z AND H:

A NONSI NGULAK N X N (REAL) MATEIX:

$N X$ N SY AMETFIC, NONNEGATIVE DEFINITE (KEAL) MATRICES.

AN $N X N$ AREAY CONTAINING THE UNIQOE POSITTVE (OE NONNEGATIVE) DEFINITE SOLUTION OF THE RICCATI EQUATION:
BI 000010

RIC 00020

RIC 00030

RIC 00040

RICO0050

RIC 00060

RIC 00070

RIC 00080

RI C00090

AIC00100

RIC00110

BICO0 120

RICO0 130

RICO0 140

RIC 00150

BIC00160

RIC00170

RIC00180

EICOO 190

RIC00200

RIC 00210

RIC00220

RIC 00230

EI C00240

RIC00250

RIC00260

RIC00270

RICO0280

RIC 00290

RIC 00300

RIC00310

RIC00320

RI C00330

RIC 00340

RIC 00350

RIC00360

RIC00370

AIC00380

RIC00390

RICO0400

RIC 00410

AIC00420

RIC 00430

RIC00440

RICOO450

RIC 00460

R IC00470

RICOO480

RIC 00490

BIC 00500

RIC00510

RIC00520

RIC00530

RIC00540

AIC 00550 


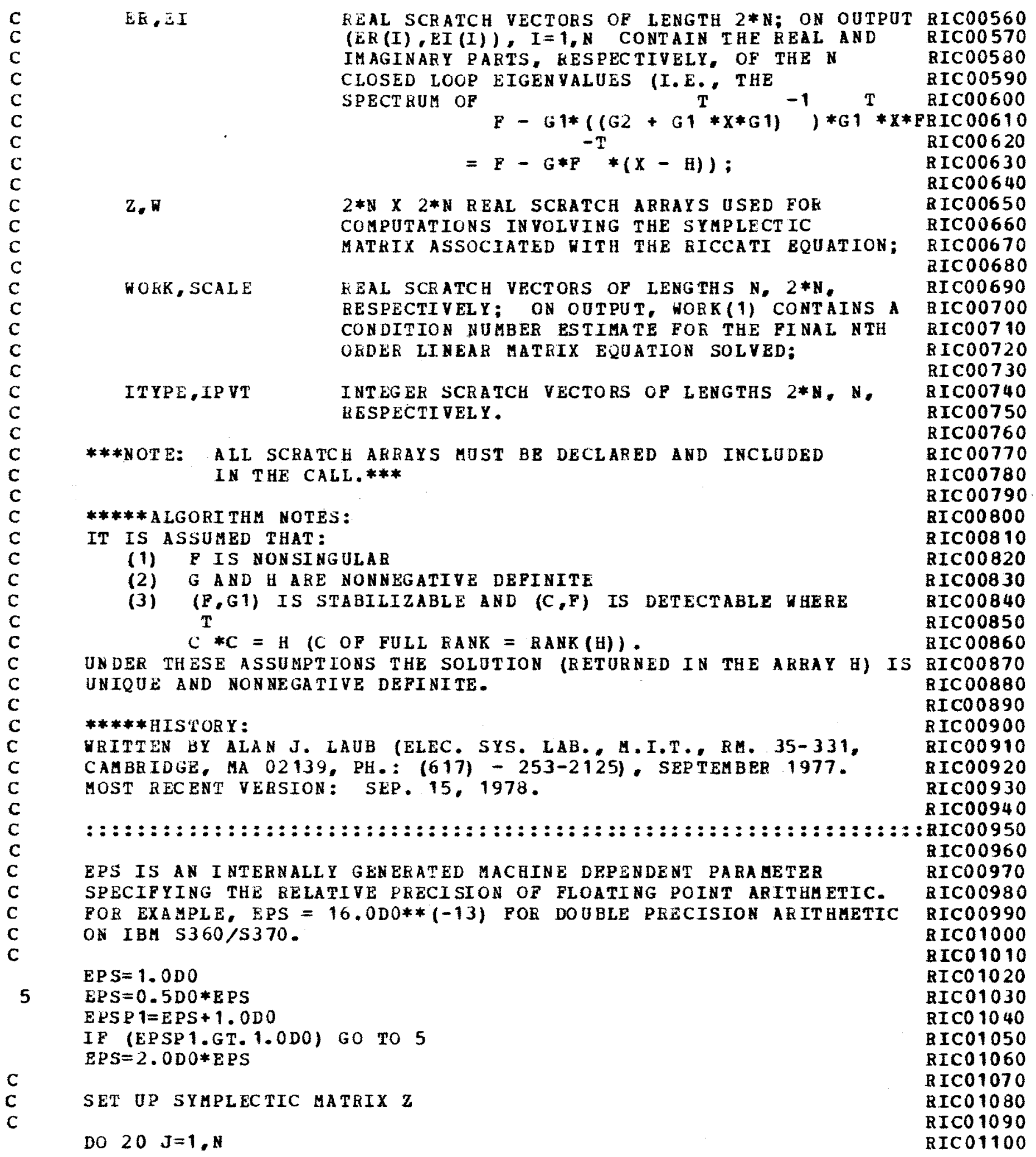


10

20

50

60

70

80

90

100

110

120

130

140

C

C

c

c

C

C

C
Do $10 I=1, N$

CONIINUE

$$
S(N+I, N+J)=F(J, I)
$$

CONINUE

CALL DUCOAP (NF, N,P,COND, IEVT, WOEK)

CONDP $1=$ COND + 1. ODO

IP (CONDP 1:GT.CCND) GO TO 30

WRITE $(6,44400)$

44400 FURMAT (42H1F MATRIX IS SINGULAE TO WORKING PEECISION) REIURN

30 DO $60 \quad \mathrm{~J}=1, \mathrm{~N}$

DO $40 \quad I=1, N$

$$
\text { WOKK }(I)=0.0 \mathrm{DO}
$$

CONTINUE

WCtK $(J)=1.000$

CALL DSOLVE (NP,N, F, WORK, IPVT)

DC $50 \quad I=1, N$

$$
\text { CONTINUE }
$$$$
Z(I, J)=\text { WOKK (I) }
$$

CONTINUE

$$
\begin{gathered}
\text { DO } 80 \mathrm{~J}=1, \mathrm{~N} \\
\text { DO } 70 \mathrm{I}=1, \mathrm{~N} \\
\mathrm{~F}(\mathrm{I}, \mathrm{J})=\mathrm{Z}(\mathrm{I}, \mathrm{J}) \\
\text { CONTINUE }
\end{gathered}
$$

CONTI INUE

CALL MOLWOA (NH, NF, N,H,F, WORK)

DO $120 \mathrm{~J}=1, \mathrm{~N}$

$$
\text { DO } 90 \quad I=1, N
$$$$
Z(I, N+J)=0.0 D 0
$$$$
Z(N+I, J)=H(I, J)
$$

$$
\text { CONTI NUE }
$$

$$
\text { DO } 110 \mathrm{~K}=1, \mathrm{~N}
$$$$
\text { Do } 100 \quad I=1 \text {, N }
$$

$$
\text { CONTINUE }
$$$$
Z(I, N+J)=Z(I, N+J)+F(I, K) * G(K, J)
$$

\section{CONTI NUE}

CONTINUE

CALL MULWOB (NH, NG, N,H, G, WOKK)

DO $140 \mathrm{~J}=1, \mathrm{~N}$

DO $130 \quad I=1, N$

$$
\text { CONTINUE }
$$$$
Z(N+I, N+J)=Z(N+I, N+J)+G(I, J)
$$

\section{CONTINUE}

BALANCE Z

CALL BALANC (NZ, NN, Z, LOW, IGH, SCALE)

FEDUCE Z TO REAL SCHUR FORA ITH EIGENVALUES OUTSIDE THE UNIT

DISK IN THE UPPER LEFT N $X$ N UPPER QUASI-TRIANGULAR BLOCK

NLOW $=1$

$N U P=N N$

CALL ORTHES (NZ, NN, NLON, NUP, Z,ER)

CALL ORTRAN (NZ,NN,NLOW,NUP,Z,ER,W)
RICO 1110

RIC01120

RIC01130

RIC01140

RICO1150

RIC0 1160

RIC 01170

RICO 1180

RIC 01190

RICO 1200

RIC01210

RICO 1220

RIC01230

RIC 01240

RIC0 1250

RIC 01260

RICO 1270

RIC 01280

BIC01290

RIC 01300

RICO1310

RIC01320

RIC 01330

RIC01340

RICO 1350

RICO 1360

EICO 1370

RIC0 1380

RICO 1390

RICO 1400

RIC 01410

RI CO 1420

RIC01430

RIC 01440

RIC01450

RICO1460

RICO 1470

BIC01480

RI CO 1490

RIC 01500

RICO 1510

RIC 01520

RI C0 1530

RIC01540

RIC0 1550

RIC01560

RIC 01570

RI CO 1580

RIC01590

RIC0 1600

RIC01610

RIC 01620

RIC01630

RIC 01640

RIC0 1650 
c

C

150

160

CONTINUE

CALL HQK3 (Z,W,NN, NLOW, NUP,ERS, ER, EI, ITYPE, NZ,NZ)

COMPULE SOLUTION OF THE EICCATI EQUATION EQOM THE OBTHOGONAL MATIIX NOW IN THE AREAY W. STORE THE RESULT IN THE ARRAY H.

CALL BALBAK (NZ,NN,LOW, IGH,SCALE,NN,W)

DO $160 \mathrm{~J}=1, \mathrm{~N}$

DO $150 \quad I=1, N$

$F(I, J)=W(J, I)$

$H(I, J)=(\mathrm{H}+\mathrm{J}, \mathrm{I})$

CONTINUE

CALL MLINEQ (NF, NH, N,N,F,H,COND, IPVT, NOKK)

C

hOKK $(1)=$ COND

C TRANSFORM TO GET THE CLOSED LOOP SPECTRUM

c

DO $190 I=1, N$

IF (ITYPE(I) .GE,0) GO TO 170

HRITE $(0,44410) I$

44410

FORMAT $(1 \mathrm{X}, \mathrm{I4}, 1 \mathrm{X}$, RETURN

170 IF (ITYPE(I).GT.0) GO TO 180

$E R(I)=1.000 / E R(I)$

$\operatorname{RI}(I)=0.000$

180

GO TO 190

IF (ITYPE (I) E EQ.2) GO TO 190

$\mathrm{T}=\mathrm{ER}(I) * 2+\mathrm{BI}(\mathrm{I}) * * 2$

$\operatorname{ER}(I)=\operatorname{ER}(I) / T$

$\mathrm{EI}(\mathrm{I})=\mathrm{EI}$ (I) $/ \mathrm{T}$

$E R(I+1)=E R(I)$

$E I(I+1)=-E I(I)$

190 CONTINUE

RETURN

C

C LAST LINE OF RICUSD

c

END
R IC 01660

RICO 1670

RIC01680

RIC01690

RIC 01700

RIC01710

RIC01720

RIC 01730

RICO 1740

BIC 01750

RIC01760

RIC01770

RICO 1780

RIC 01790

RICO 1800

RIC 01810

RICO 1820

RICO1830

R IC 01840

RIC01850

RIC 01860

RI C0 1870

BIC 01880

RIC0 1890

RIC01900

RIC0 1910

RIC01920

RIC0 1930

RIC01940

RIC01950

RIC0 1960

R IC 01970

RICO 1980

RIC01990

RIC02000

RIC0 2010

BIC 02020

RI CO 2030 
NA

ROW DIMENSION OF THE ARBAY CONTAINING A AS DECLAFED IN THE CALLING PROGRAM DIUENSION STATEMEN T;

N

A

OKDEE OF THE MATRIX;

N X N MATRIX TO BE TRIANGULARIZED.

ON OUTPUT:

A

COND

IP VT

WORK i X ARRAY CONTAINING AN UPPER TRIANGULAR MATEIX U AND A PERMUTED VERSION OF A LOWER TEIANGULAR MATEIX I-L SO THAT (PERMUTATION MATKIX) $* A=L * 0$.

AN ESTIMATE OF THE CONDITION OF A FOR THE LINEAR SYSTEM

$$
A * X=B \text {. }
$$

CHANGES IN a and B MAY CAUSE CHANGES COND TIMES AS LARGE IN $X$. IF COND + 1.0DO = COND, A IS SINGULAE TO WOKKING PEECISION. COND IS SET TO 1.0D+32 IF "EXACT" SINGULARTTY IS DETECTED.

PIVOT VECTOR CF LENGTH N. IPV $T(K)=T H E$ INDEX OP THE $K-T H$ PIVOT ROW. IPVT (N) $=(-1) * *$ (NU GBER OF INTERCHANGBS).

REAL SCEATCH VECTOE OF LENGTH N. ITS INPUT CONTENTS ARE IGNORED. ITS OUTPUT CONTENTS ARE USUALLY UNIMPORTANT.
DDC 00210 $\mathrm{DDC} 00220$ DDC 00230 DDCO0240 DDC00250 DDC00260 DDC00270 DDC 00280 DDC00290 DDC 00300 $D D C 00310$ DDC00320 DDC 00330 DDCDO340 DDC00350 DDC 00360 DDC 00370 DDC00380 DDC 00390 DDC00400 DDC00410 DDCOO420 DDC00430 DDCO0 440 DDC00450 DDC00460 DDCO0470 DDC00480 DDC 00490 DDC00500 DDC 00510 DDC00520 DDC00530 DDC00540 DDC00550 
*****APELICATIONS AND USAGE RESTKICTIONS:

DDC 00560 DUCOAP CAN BE USED IN CONJUNCTION UITH DSOLVE TO COMPUTE SOLUTIONSDDCOO570 TO SYSTEMS OF LINEAR EQUATIONS. IF NEAR-SINGULAEITY IS DDC00580 DETECTED SOLUTIONS AKE MORE RELIABLY COMPUTED VIA SINGULAR DDC00590 VALUE DECOMPOS ITION OF A. DDCOMP CAN ALSO BE USED TO COMPUTE THE DETERMINANT OF A. DDC00600 ON OUTPUT SIMPLY COMPUTE: $\operatorname{DET}(A)=\operatorname{IPVT}(N) * A(1,1) * A(2,2) * \ldots . * A(N, N)$. DDC00610 DDC00620 DDC00630 DDC00640

*****ALGORITHE NOTES: DDC 00650 DDCOMP IS A DOUBLE PFECISION ADAPTATION OF THE SUBROUTINE DECOMP DDC00660 (SEE REFERENCE (1) FOR DETAILS). THIS ALGORITHU IMPLELENTS GAUSSIAN ELIMINATION IN A MODERATELY UNCONVENTIONAL MANNER $D D C 00670$ TO PEOVILE POTENTIAL EFPICIENCY ADVANTAGES UNDER CERTAIN OPERATING SYSTEMS (SEE REFERENCE (2) FOR DETAILS).

DDC00680

DDC00690

$\mathrm{DDC} 00700$

DDC007 10

*****REFERENCES :

(1) FORSYTHE,G.E., MALCOLM, M.A., AND MOLER,C.B., COMPUTER DDC 00720 $D D C 00730$ METHODS FOR MATHEMATICAL COMPUTATIONS, PRENTICE-HALL, 1977. MOLER,C.B.. MATRIX COMPUTATIONS WITH PORTRAN AND PAGING, COMM. ACM, 15(1972), 268-270.

DDC 00750

DDC 00760

*****HISTORY:

ADAPTATION AND DOCOMENTATION WRITTEN BY ALAN J. LAUB

(ELEC. SYS. LAB., M.I.T., RM. 35-331, CAMBRIDGE, MA 02139 . PH.: (617)-253-2125), AUG UST 1977 .

MOST RECENT VERSION: SEP. $21,1977$.

DDC00770

DDC00780

DDC00790

DDC00800

DDC00810

DDC00820

DDC00830

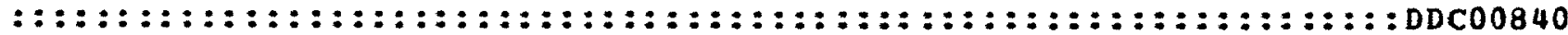

$\operatorname{IPVT}(N)=1$

IF (N.EQ.1) GO TC 80

DDC00850

DDC00860

$D D C 00870$

N $1=N-1$

DDC00880

c

COMPUTE 1-NOBM OF A

DDC 00890

DDC00900

DDC00910

A NOB I $=0.0 \mathrm{DO}$

DO $10 \mathrm{~J}=1, \mathrm{~N}$

$\mathrm{T}=0.000$

DO $5 I=1, N$

$T=T+D A B S(A(I, J))$

5

CONTINUE

IF ( $\mathrm{T} . \mathrm{GT}$. A NORM) ANORM=T

10 ContInUE

GAUSSIAN ELIMINATION WITH PARTIAL PIVOTING

DDC 00920

DDC00930

DDC00940

DDC00950

DDC 00960

DDC00970

DDC00980

DDC00990

DDC01000

DDC 01010

DO $35 k=1$, N 1

KP $1=K+i$

DDC0 1020

DDC 01030

DDC0 1040

DDC0 1050

FIND RIVUT

$M=K$

DO $15 I=K P 1, N$

IF (DABS $(A(I, K)), G T \cdot D A B S(A(M, K))) \quad M=I$

DDC0 1060

DDC01070

DDC 01080

DDC0 1090

DDC 01100 
C

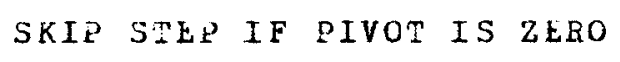

C

C

20

C

C

\section{CONT I NIJ E}

CONTINUE

DO $20 \mathrm{I}=\mathrm{KP} 1, \mathrm{~N}$

CONTINUL

$$
A(I, K)=-A(I, K) / T
$$

INTERCHANGE AND ELIMINATE BY COLUMNS

DC $30 \quad J=K P 1, N$

$T=A(M, J)$

$A(M, J)=A(K, J)$

$A(K, J)=T$

IF $(\mathrm{T} . \mathrm{EQ} \cdot 0.0 \mathrm{DO})$ GO TO 30

DO $25 I=K P 1, N$ CONTINUE $A(I, J)=A(I, J)+A(I, K) * T$

COND $=(1-N O R$ O OF A) * (AN ESTIMATE OF 1-NORM OF A-INVERSE). ESTIMAZE OBTAINED BY ONE STEP OF INVERSE ITERATION FOR THE SHALL SINGULAR VECTOK. THIS INVOLVES SOLVING THO SYSTEMS $T$

OF EUUATIONS: $A * Y=E$ AND $A * Z=Y$ WHERE $E$

IS A VECTOR OF +1 OR -1 CHOSEN TO CAUSE GROWTH IN $Y$. ESTIMATE $=(1-$ NOKM OF Z $) /(1-N C K M$ OF $Y)$.

$$
\text { SOLVE } \quad A^{T} * Y=E
$$

DO $50 \mathrm{~K}=1, \mathrm{~N}$

$\mathrm{T}=0.0 \mathrm{DO}$

IF (K. EQ.1) GO TO 45

$\mathrm{KM} 1=\mathrm{K}-1$

DO $40 I=1, K M 1$ $\mathrm{T}=\mathrm{T}+\mathrm{A}(\mathrm{I}, \mathrm{K}) *$ WORK$(\mathrm{I})$

40 CONTINUE

45

50

$E K=1.0 D 0$

IF $(T . L T \cdot 0.0 D O) \quad E K=-1.000$

IF $(A(K, K) \cdot E Q \cdot 0.0 D 0)$ GO TO 90

WORK $(K)=-(E K+T) / A(K, K)$

CONTINOE

DO $60 \mathrm{~KB}=1$, NB 1

$\mathrm{K}=\mathrm{N}-\mathrm{KB}$

DDC 01110

DDC01120

DDC 01130

DDCO 1140

DDC 01150

DDC01160

$D D C 01170$

DDC0 1180

DDCO1190

DDC0 1200

DDC01210

DDC 01220

DDCO 1230

DDC01240

DDC0 1250

DDC01260

DDC 01270

DDC0 1280

DDC01290

DDC0 1300

D DC01310

DDC 01320

DDCO 1330

DDC 01340

DDCO 1350

DDC 01360

DDC0 1370

DDC01380

DDC0 1390

DDC01400

DDC 01410

DDC0 1420

DDC 01430

DDCO 1440

DDCO1450

DDC0 1460

DDC0 1470

DDC0 1480

DDC01490

DDC 01500

DDC0 1510

DDC01520

DDC01530

DDC0 1540

DDC 01550

DDC0 1560

DDC 01570

DDC0 1580

DDC01590

DDC0 1600

DDC01610

DDC0 1620

DDC0 1630

DDC 01640

DDC0 1650 
CONTINUE
WOKK $(K)=T$

$T=0.000$

$K P 1=K+1$

DO $55 I=K P 1, N$

$T=T+A(I, K) * W O R K(K)$

$M=I P V T(K)$.

IF (M.EQ.K) GO TO 60

$\mathrm{T}=W \mathrm{WKK}(\mathrm{M})$

WORK (M) = WCRK (K)

WORK $(K)=T$

60 CUNTINUE

C

YNOEM $=0.0 \mathrm{DO}$

DO $65 I=1, N$

YNOKM = YNOKM+DABS (HORK (I))

65 CONTINUE

C

C

SOLVE $\quad A * Z=Y$

CALL DSOLVE (NA,N,A, HORK, IPVT)

C

ZNORH $=0.000$

DO $70 \quad I=1, N$

2NORM $=\mathrm{ZNOHM}+\mathrm{DABS}$ (WORK (I))

70 CONTINUE

C ESTIMATE CONDTTION

C COND=ANORM*ZNOEM $/$ NORM

IE (COND.LT. 1.ODO) COND $=1.0 D O$

RETUEN

c

C 1-BY-1 CASE

$80 \quad \operatorname{COND}=1.0 \mathrm{DO}$

IF $(A(1,1), N E .0 .0 D O)$ RETURN

C

C "EXACI" SINGULARITY

$90 \quad \operatorname{COND}=1.0 \mathrm{D}+32$

EETURN

C

C LAST LINE OF DDCOMP

C

END

DDC0 1660

DDC 01670

DDCO 1680

DDC 01690

DDC0 1700

DDC01710

DDC 01720

DDC0 1730

DDC 01740

DDC0 1750

DDC 01760

DDC 01770

DDC01780

DDC 01790

DDC0 1800

DDC 01810

DDC0 1820

DDC0 1830

DDC 01840

DDC0 1850

DDC01860

DDC0 1870

DDCO 1880

DDC 01890

DDCO 1900

DDC01910

DDCO 1920

DDC0 1930

DDC 01940

DDCO 1950

DDC0 1960

DDCO 1970

DDC01980

DDC 01990

DDC02000

DDC 02010

DDC02020

DDC02030

DDCO 2040

DDC02050

DDC 02060

DDC02070

DDC 02080

DDC02090

DDC02 100

DDCO 2110 
C

SUBKOUTINE DSOLVE (NA, N, A, B, IPVT)

D SO00010

DSO00020

ט 5000030

****2AKAIETERS:

INTEGET NA, N, IPVT (N)

DOUBLE PKECISION A (NA,N),B(N)

c

*****iOCAL VAFIABLES:

LNTEGEE K3,KM1,NI1,KP1,I,K,M

DOUBLE PRECISION T

DSO00040

D SO00050

DS 000060

DS000070

DSO00080

DSO00090

DSO00100

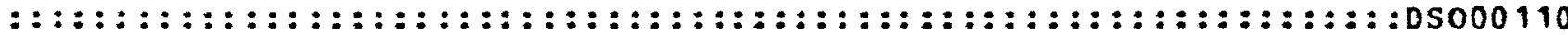

DSO00120

*****2UEPOSE:

DSO00130

IHLS SJBKOUTINE SOLVES THE LINEAR SYSTEM $A * X=B$

BY FCRWATD ELIMINATION AND BACK SUBSTITUTION USING THE

TEIANGULAII FACTOKS OF A PROVIDED BY DDCOMP.

DS 000140

DS000150

DS 000160

DSO00170

****? 2 ARAMETBR DESCR IPT ION:

ON INPUT:

NA

FOW DIMENSION OF THE ARRAY CONTAINIRG $A$

DSO00180

DSO00190

D 5000200

DSO00210

DSO00220

AS DECLARED IN THE CALLING PROGRAM DIMENSION STATEMENT:

DS000230

N ORDER OF THE MATRIX A :

DSO00240

DSO00250

DSO00260

A TEIANGULARIZED MATRIX OBTAINED FROM DDCOMP:

DSO00270

DSO00280

B RIGH HAND SIDE VECTOR OF LENGTH N;

DSO00290

I PV T

PI VCT VECTOK OF LENGTH N OBTAINED FROA DDCOMP.DSO00310

DSO00320

ON OUTPUT:

DS 000330

B

SOLUTION VECTOE, $X$, OF LENGTH $N$

S000340

DSO 00350

DSO00360

*****APPLICATIONS AND OSAGE RESTEICTIONS:

DSOLVE SHOULD NOT BE USED IN CASE DDCOMP HAS DETECTED NEAR-

DS 000370

SINGULAKITY. SINGULAR VALUE ANALYSIS IS THEN MOBE RELIABLE.

DS000380

DSO00390

DSO00400

*****ALGORITHM NOTES:

DSOLVE IS A DOUBLE PRKCISION ADAPTATION OR THE SUBROJTINE SOLVE

SO00410

(SEE REFERENCE (1) IN THE DDCOMP DOCUMENTATION FOB DETAILS).

DSO00420

DSO00430

DSO00440

DSO00450

*****HISTORY:

ADAPTATION AND DCCUMENTATION WEITTEN BY ALAN J. LAUB

(ELEC, SYS. LAB., M.1.T., RM. 35-331, CAMBRIDGE, MA 02139,

PH.: (617)-253-2125), AUGUST 1977 .

MOST RECENT VERSION: SEP. 21, 1977.

DSO00460

DSO00470

DSO00480

DSO00490

DS 000500

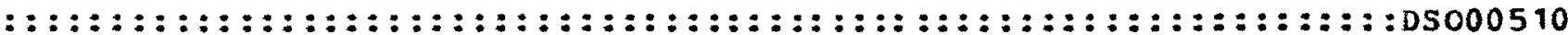

FORIARD ELIMINATION

DSO00520

DSO00530

DSO00540

IF (N.EQ.1) GO TO 50

DS000550 


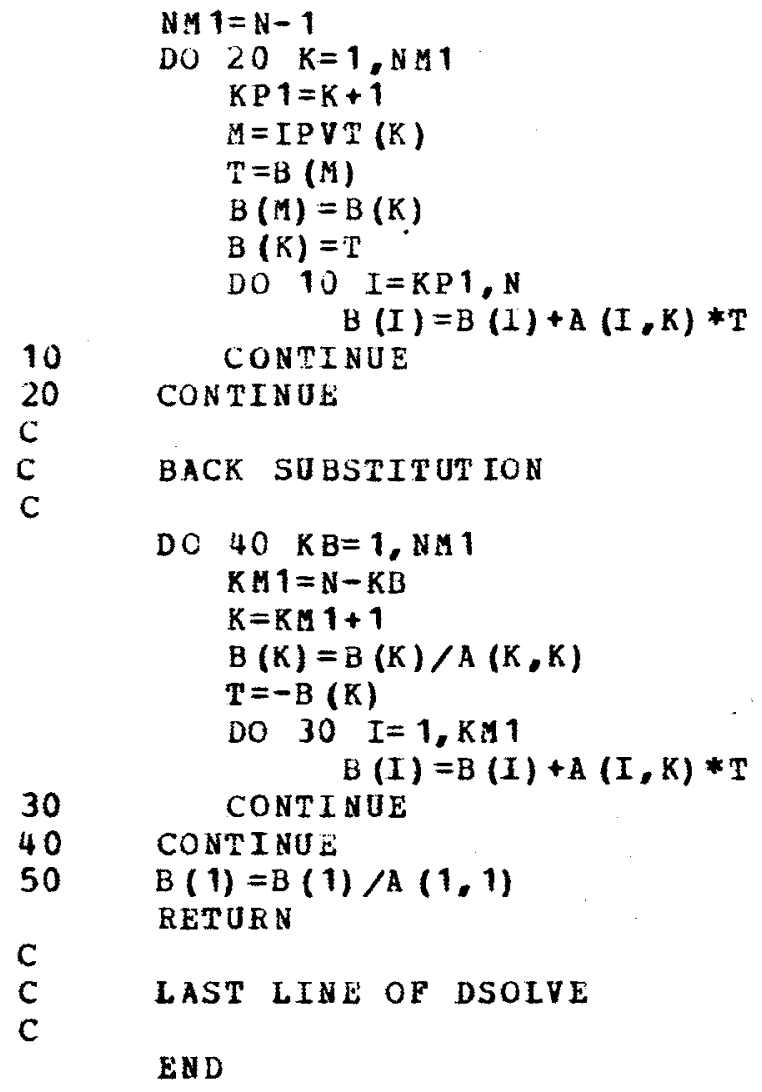

D 5000560

DSO00570

DS000580

DSO00590

DS000600

DS000610

DSO00620

D 5000630

DSO00640

DS000650

DSO00660

DS000670

DSO00680

DS000690

DS000700

DS000710

DS000720

D 5000730

DSO00740

D 5000750

DSO00760

D 5000770

DS000780

DS000790

DS000800

DSO00810

D SO 00820

DS000830

D SO00840 


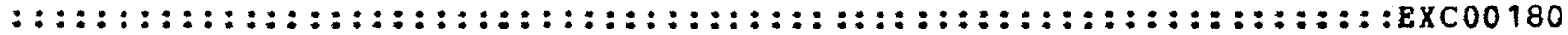

*****PURPOSE:

EXC00190

GIVEN THE UPPER HESSENBERG MATRIX A WITH CONSECUTIVE B1 X B1 AND B $2 \times$ B 2 DIAGONAL BLOCKS (B1, B2.LE.2) STARTING AT A (L,L), THIS EXC00200 SUBKOUTINE PKODUCES A UNITARY SIMILARITY TRANSFORMATION THAT EXCHANGES THE BLOCKS ALONG VITH THEIE EIGENVALUES. THE TKANSFOAMATION IS ACCUMULATED IN $V$.

EXC00210

ExC00220

ExC00230

ExC00240

ExC00250

*****P ARALETER DESCBIPTION:

$\operatorname{ExC} 00260$

$\mathrm{EXC00270}$

ON INPUT: $N A, N V$

RO DIUENSIONS OP THE AREAYS CONTAINING A $\operatorname{ExC} 00280$

ExC00290

$\operatorname{ExC00300}$ CALLING PROGRAM DIMENSION STATEMENT;

ExCO0310

ExC00320

$\AA$

$N X$ N MATKIX WHOSE BLOCKS ARE TO BE INTERCHANGED;

Exco0330

EXC00340

$\operatorname{ExC} 00350$

N ORDER OF THE MATRIX A;

EXC00360

L POSITION OF IHE BLOCKS;

ExC 00370

ExC00380

EXC00390

B 1

AN INTEGER CONTAINING THE SIZE OF ThE FIRST

EXCOO400 BLOCK ;

EXC00410

ExC00420

B2

AN INTEGER CONTAINING THE SIZE OF THE SECOND BLOCK ;

ExCO0 430

ExC00440

ExC00450

EPS

A CONVERGENCE CRITERION (CF - HQR3) -

EXC00460

$\mathrm{E} \times \mathrm{C} 00470$

ON OUTPUT:

FAI L A LOGICAL VARIABLE WHICH IS . PALSE. ON A
NORMAL RETURN. IF THIRTY ITERATIONS WERE
PERFORMED HITHOUT CONVRGENCE, FAIL IS SET TO
TRUE. AND THE ELEMENT A(L+B2, L+B2-1) CANAOT
BE ASSUMED 2ERO.
EXC00480

ExC00490

ExC00500 EXC00510 exc00520 ExC00530 ExC00540 ExC00550 


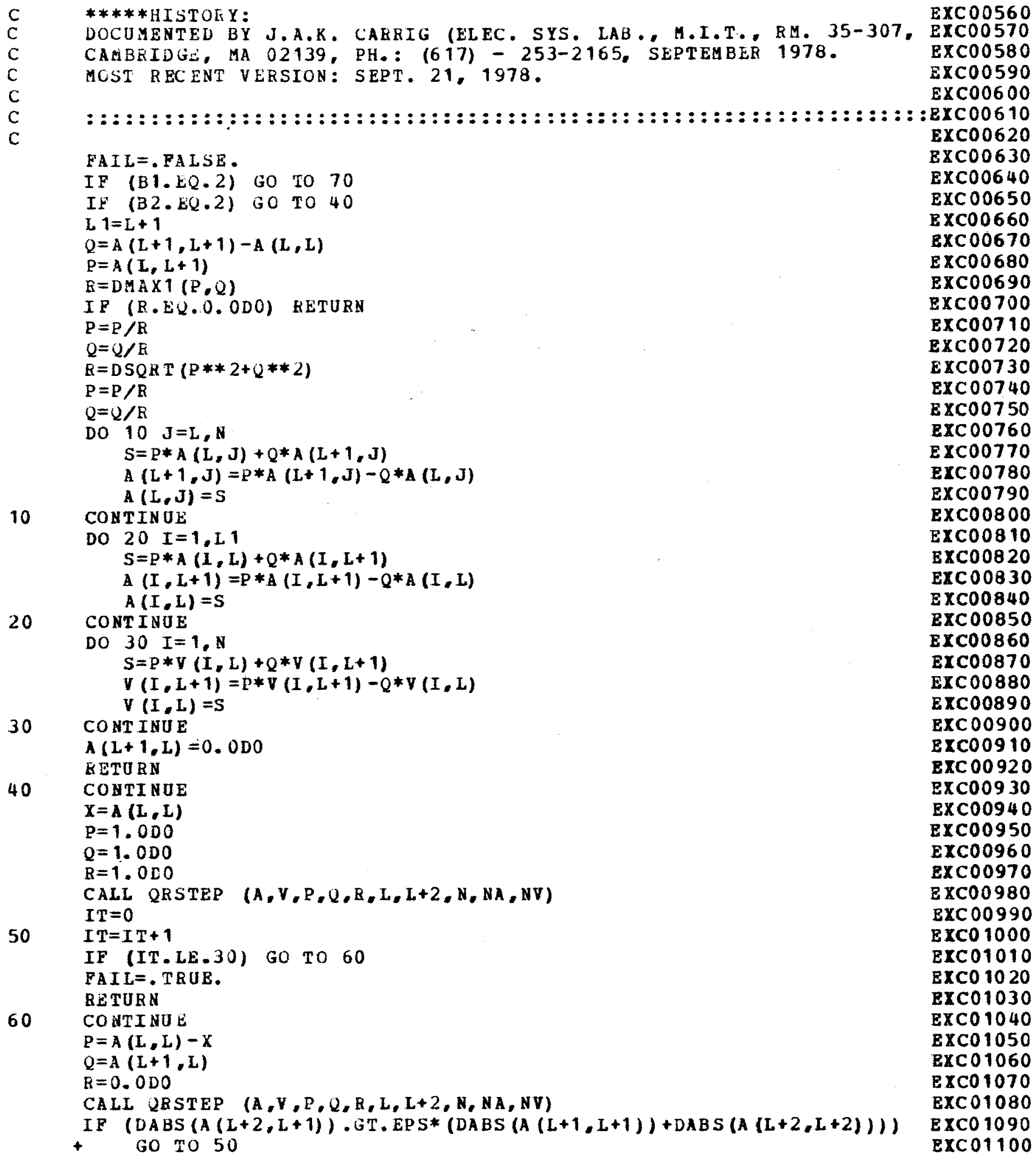


$A(L+2, L+1)=0.000$

KCTUKN

70

CONT INUE

$M=L+2$

IF (B2.LQ.2) $\quad M=M+1$

$X=A(L+1, L+1)$

$Y=A(L, L)$

$w=A(L+1, L) * A(L, L+1)$

$\mathrm{P}=1.0 \mathrm{DO}$

$Q=1.000$

$R=1.0 \mathrm{DO}$

CALL QRSTEP (A, Y,P, Q, K, L, M,N,NA,NV)

$I T=0$

$80 \quad I T=I T+1$

IF (IT.LE.30) GO TO 90

FAIL $=$. TRUE.

RETURN

CONTINUE

$Z=A(L, L)$

$\mathrm{R}=\mathrm{X}-\mathrm{Z}$

$\mathrm{S}=\mathrm{Y}-\mathrm{Z}$

$\mathrm{P}=(\mathrm{L} * \mathrm{~S}-W) / \mathrm{A}(\mathrm{L}+1, L)+\mathrm{A}(L, L+1)$

$Q=A(L+1, L+1)-Z-R-S$

$R=A(L+2, L+1)$

$S=D A B S(P)+D A B S(Q)+D A B S(K)$

$\mathrm{P}=\mathrm{P} / \mathrm{S}$

$Q=Q / S$

$\mathrm{R}=\mathrm{R} / \mathrm{S}$

CALL QRSTEP $(A, V, P, Q, K, L, M, N, N A, N V)$

IF (DABS (A $(M-1, M-2)) \cdot G T$. EPS* (DABS $(A(M-1, M-1))+D A B S(A(M-2, M-2))))$

+ GO TO 80

$A(M-1, M-2)=0.000$

$\mathrm{C}$

BETURN

C LAST LINE OP EXCHNG

END

$\operatorname{ExC} 01110$

EXCO 1120

EXC 01130

ExC01140

ExC01150

EXCO 1160

ExC01170

ExC0 1180

$\mathrm{ExC} 01190$

ExC 01200

EXCO 1210

ExC01220

ExC01230

ExC01240

ExCO 1250

EXC01260

ExC0 1270

EXC0 1280

ExC 01290

ExC0 1300

ExC01310

EXCO 1320

ExCO 1330

ExC 01340

ExC01350

EXC01360

EXCO 1370

ExC01380

ExC01390

EXC01400

ExC01410

EXCO 1420

EXC 01430

EXCO 1440

ExC 01450

EXC01460

EXC01470 


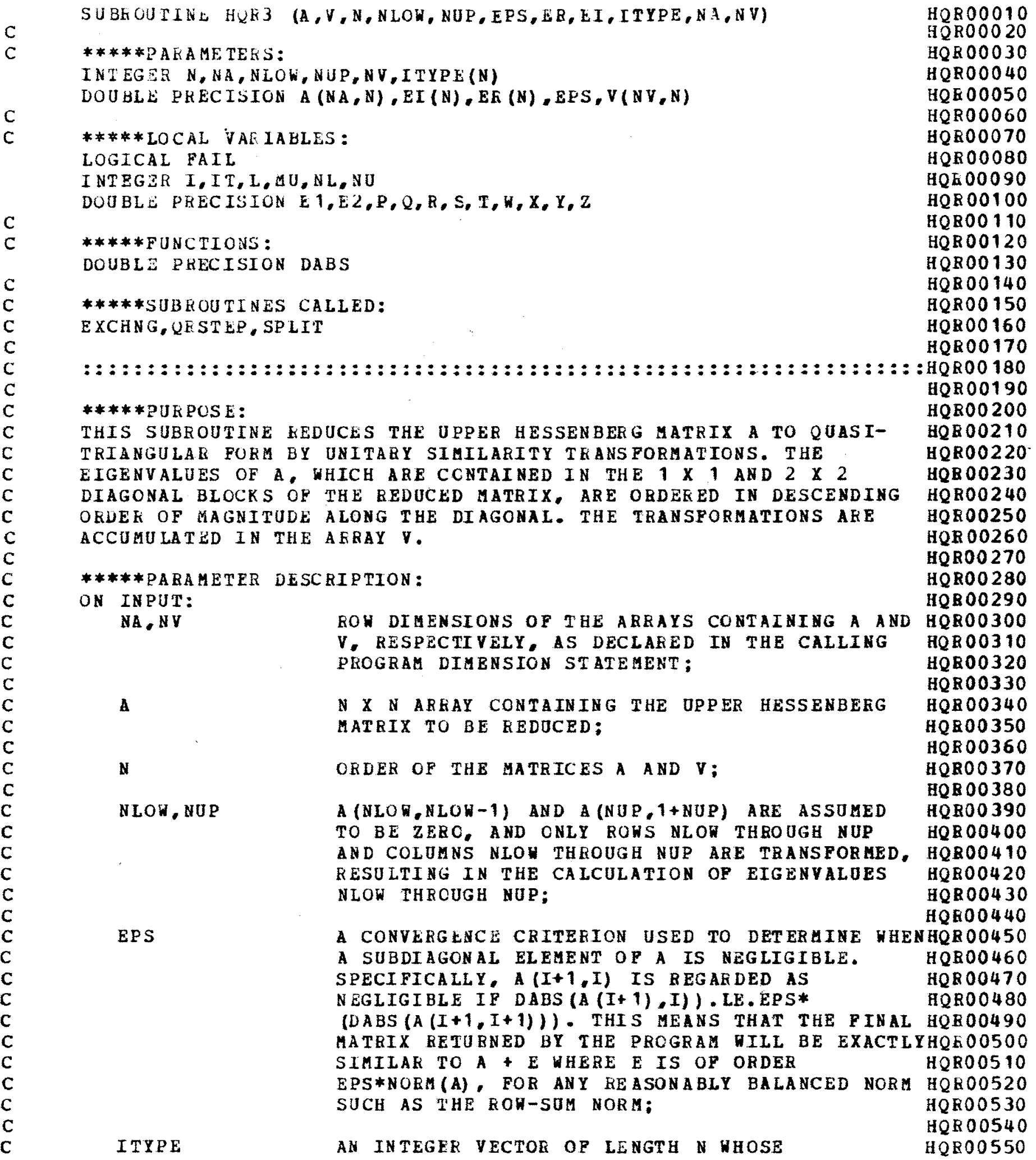


$\mathrm{C}$
$\mathrm{C}$
$\mathrm{C}$
$\mathrm{C}$
$\mathrm{C}$
$\mathrm{C}$
$\mathrm{C}$
$\mathrm{C}$
$\mathrm{C}$
$\mathrm{C}$
$\mathrm{C}$
$\mathrm{C}$
$\mathrm{C}$
$\mathrm{C}$
$\mathrm{C}$
$\mathrm{C}$
$\mathrm{C}$
$\mathrm{C}$
$\mathrm{C}$
$\mathrm{C}$
$\mathrm{C}$
$\mathrm{C}$
$\mathrm{C}$
$\mathrm{C}$
$\mathrm{C}$
$\mathrm{C}$
$\mathrm{C}$
$\mathrm{C}$

10

20

30

40

50

60
I-TH ENTEY IS

0 IF THE I-TH EIGENVALUE IS KEAL,

1 IF THE I-TH EIGENVALUE IS COMPLEX WITH POSITIVE IMAGINARY PART,

2 IF THE I-TH EIGENVALUE IS COMPLEX ITH NEGATIVE IMAGINARY EART,

-1 IF THE I-TH EIGEN VALUE WAS NOT CALCULATED SUCCESSFULIY.

$$
\text { ON OUTPUT: }
$$

\section{A}

V

ER, EI
N X N ARBAY CCNTAINING THE EEDUCED, QUASITKIANGULAE MATRIX:

$N X$ N AFAY CCNTAINING THE REDUCING TKANSPORMATIONS TO BE MULTIPLIED;

REAL SCRATCH VECTORS OF LENGTH N WHICH ON HETURN CONTAIN THE REAL AND IMAGINAKY PAETS, RESPECTIVEL $Y$, OF THE EIGENVALUES.
HQR 00560 HQR 00570 HQROO 580 HQR00590 HQE 00600 HQR 00610 HQK00620 HQR 00630 HQR0O640 HQR 00650 HQF 00660 HQR 00670 HQROO680 HQR00690 HQR 00700 HQR 00710 HQR 00720 HQR0O730 HQR 00740 HQROO 750 HQR 00760 HQR00770

\section{*****HISTORY:}

DOCUMENTLD BY J.A.K. CARRIG, (ELEC. SYS. LAB.. M.I.T., RM. 35-307,HQR00780 CAMBRIDGE, MA 02139, PH.: (617)-253-2165), SEPT 1978. MOST RECENT VERSION: SEPT $21,1978$.

HQR 00790 BQR00800 HQR 00810

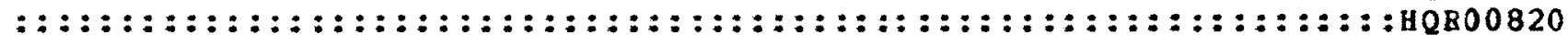

DO $10 I=N L O W, N O P$ ITYPE (I) $=-1$

CONTINUE

$\mathrm{T}=0.0 \mathrm{DO}$

NU $=$ NUP

IF (NU.LT.NLOW) GO TO 240

$$
\mathrm{IT}=0
$$

CONTINUE

$$
\mathbf{L}=\mathrm{NU}
$$

CONTINUE

IF (L.EQ.NLOW) GO TO 50

IF $(\operatorname{DABS}(A(L, L-1)), L T \cdot \operatorname{LPS} *(\operatorname{DABS}(A(L-1, L-1))+\operatorname{DABS}(A(L, L))))$

$+$ GO TO 50

$L=L-1$

GO TO 40

CONT INUE

$X=A(N U, N U)$

IF (L. EQ.NU) GO TO 160

$Y=A(N U-1, N U-1)$

$\mathrm{H}=\mathrm{A}(\mathrm{NU}, \mathrm{NU}-1) * \mathrm{~A}(\mathrm{NU}-1, \mathrm{NU})$

IF (L.EQ.NU-1) GO TO 100

IF (IT. BQ.30) GO TO 240

IF (IT.NE.10,AND. IT.NE.20) GO TC 70

$\mathrm{T}=\mathrm{T}+\mathrm{X}$

DO $60 \quad I=N L O W, N U$

$$
A(I, I)=A(I, I)-X
$$

CONTINUE
HQR 00830

HQR00840

HQB 00850

HQROO 660

HQR 00870

HQE 00880

HQROOB9O

HQR 00900

HQROO9 10

HQR 00920

HOROO 30

HQROO 940

HQR 00950

HQR00960

HQR00970

HQRO0980

HQB 00990

HQR 01000

HQR 01010

HQRO 1020

HQB 01030

HQRO 1040

HQR 01060

HQRO 1070

HQR 01080

HQRO 1090

HQR 01100
HQRO 1050 
$S=D A B S(A(N U, N U-1))+\operatorname{DABS}(A(N U-1, N U-2))$

$\mathrm{X}=0.7500 * \mathrm{~S}$

$Y=X$

70

$W=-0.437500 * S * * 2$

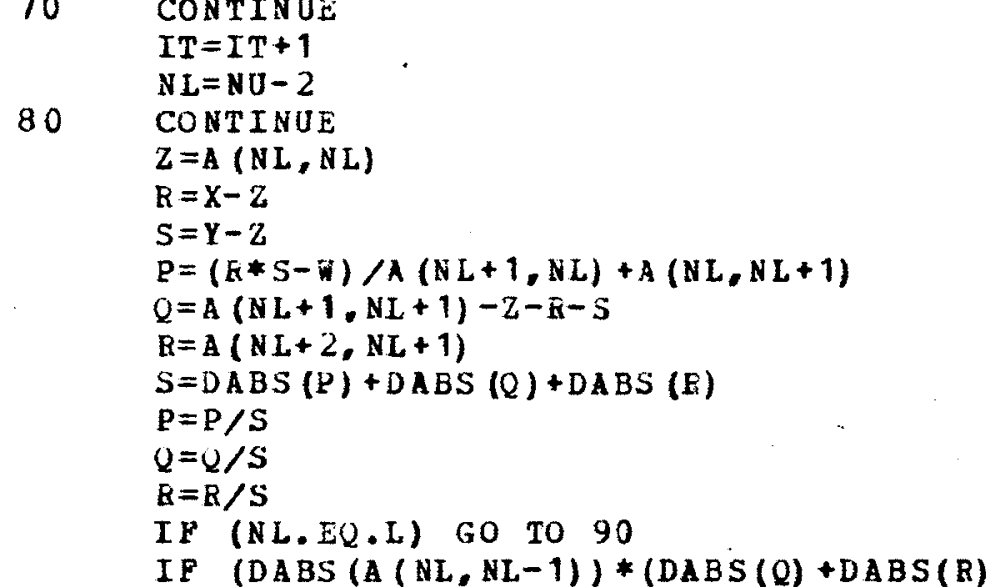

$I T=I T+1$

$N L=N U-2$

$\mathrm{R}=\mathrm{X}-\mathrm{Z}$

$\mathrm{S}=\mathrm{Y}-\mathrm{Z}$

$P=(E * S-N) / A(N L+1, N L)+A(N L, N L+1)$

$Q=A(N L+1 . N L+1)-Z-F-S$

$R=A(N L+2, N L+1)$

$\mathrm{P}=\mathrm{P} / \mathrm{S}$

$Q=Q / S$

IF (NL.EQ.L) GO TO 90

IF (DABS (A (NL, NL-1))*(DABS (Q) +DABS (R)) - LE.EPS*DABS (P) *

$N \mathrm{~L}=\mathrm{NL}-1$

GO TO 80

90 CONTINUE

CALL QRSTEP $(A, V, P, Q, R, N L, N O, N, N A, N V)$

GO TO 30

100 IF (NU - NE.NLON +1) A(NU-1,NU-2) =0.0DO

$A(N U, N U)=A(N U, N U)+T$

$A(N U-1, N U-1)=A(N U-1, N U-1)+T$

$\operatorname{ITYPE}(\mathrm{NU})=0$

$\operatorname{ITYPE}(N U-1)=0$

$M U=N U$

110 CONTINUE

$N L=M U-1$

CALL SPLIT (A, V,N,NL,E1,E2,NA,NV)

IF (A (MU:MU-1) EQ.0.ODO) GO TC 170

IF (MU.EQ.NOP) GO TO 230

IF (MU.EQ.NUP-1) GO TO 130

IF $(\mathrm{A}(\mathrm{MU}+2, \mathrm{MU}+1) \cdot \mathrm{EQ}, 0.0 \mathrm{DO})$ GO TO 130

IF $(A(M U-1, M U-1) * A(M U, M U)-A(M U-1, M U) * A(M U, M U-1), G E, A(M U+1, M U+1) *$

$+A(M U+2, M U+2)-A(M U+1, M U+2) * A(M U+2, H U+1))$ GO TO 230

CALL BXCHNG $(A, V, N, N L, 2,2, E P S, F A I L, N A, N V)$

IF (.NOT.EAIL) GO TO 120

ITYPE (NL) $=-1$

IT YPE $(N L+1)=-1$

$\operatorname{ITYPE}(N L+2)=-1$

$\operatorname{ITYPE}(N \mathrm{~L}+3)=-1$

GO TO 240

120 CONTINUE

$\mathrm{MU}=\mathrm{MU}+2$

GO TO 150

130

CONTI NUE

IF $(A(M U-1, M U-1) * A(M U, M U)-A(M U-1, M U) * A(M U, M U-1), G E$.

$+\quad A(M U+1, M U+1) * * 2)$ GO TO 230

CALL EXCHNG (A, $, N, N L, 2,1$, ES, PAIL, NA,NV)

HQR 01110

HQRO 1120

HQB 01130

HQRO 01140

HQEO 01150

HQR 01160

HQRO 1170

HQB 01180

HQEO 1190

HQR 01200

HORO 1210

HQRO 1220

HQR01230

HQRO 1240

HQR 01250

HQRO 1260

HQR 01270

HQRO 1280

HQRO 1290

HQR 01300

HQE01310

HQR 01320

HQR 01330

HQR 01340

HORO 1350

HQRO 1360

HQR 01370

BQRO 1380

HQE 01390

HQRO 1400

HQR 01410

HQRO 1420

HQE 01430

HQRO 1440

HQRO 1450

HQR 01460

HQRO 1470

HQR 01480

BQB 01490

HQR 01500

HQR01510

HQB 01520

HQRO 1530

HOBO 1540

HQEO 1550

HQRO 1560

HOR 01570

HQRO 1580

HQR 01590

HQR 01600

HQB 01610

HQRO 1620

HQR01630

HQR 01640

HQR01650 
IF (- (NOL'FAIL) GO TO 140

$\operatorname{ITYE}(\mathrm{NL})=-1$

$\operatorname{ITYPE}(N L+1)=-1$

$\operatorname{ITYPE}(N L+2)=-1$

GO TO 240

140

CONTINU⿺

$M U=M U+1$

GO TO 110

$160 \quad N L=0$

$A(N U, N U)=A(N U, N U)+T$

IF (NU.NE.NLOW) A(NU,NU-1) $=0.000$

$\operatorname{ITXPE}(\mathrm{NU})=0$

$M U=N U$

170 CONTINUE

180 CONINUE

IF (MU.EQ.NUP) GO TO 220

IF (MU.EQ.NUP-1) GO TO 200

IF $(A(M U+2, H U+1) \cdot E Q \cdot 0.0 D O)$ GO TO 200

IF $(A(M U, M U) * * 2, G E, A(M U+1, M U+1) * A(M U+2, M U+2)-A(M U+1, M U+2) *$

$+\quad A(M U+2, M U+1))$ GO TO 230

CALL EXCHNG (A,V,N,MU, 1,2, EPS, FAIL, NA, NV)

IF (.NOT.FAIL) GO TO 190

$\operatorname{ITYPE}(M U)=-1$

$\operatorname{ITYPE}(M U+1)=-1$

$\operatorname{IT} Y P(M U+2)=-1$

GO TO 240

190 CONTINUE

$M U=M U+2$

GO TO 210

200 CONTINUE

IF (DABS (A (MU,MU)) -GE.DABS (A (MU+1, MU+1))) GO TO 220

CALL EXCHNG $(A, V, N, M U, 1,1, E P S, F A I L, N A, N V)$

$M U=M U+1$

210 CONTINUE

GO TO 180

220 CONTINUE

$M U=N L$

$N \mathrm{~L}=0$

IF (MU.NE.O) GO TO 170

230 CONTINUE

$\mathrm{NU}=\mathrm{L}-1$

GO TO 20

240 IF (NU.LT.NLOW) GO TO 260

DO $250 \quad I=1, N U$

$A(I, I)=A(I, I)+T$

250 CONTINUE

260 CONTINUE

$\mathrm{NU}=\mathrm{NUP}$

270 CONTINUE

IF (ITYPE (NU) -NE.-1) GO TO 280

$\mathrm{NU}=\mathrm{NU}-1$

GO TO 310

280

IF (NU.EQ.NLOW) GO TO 290

HQR 01660

HQKO 1670

HQE 01680

HQRO 1690

HQE 01700

HQR 01710

HQRO 1720

HQR 01730

HQRO 1740

HQRO 1750

HQRO 1760

HQRO 1770

HQRO1780

HQRO 1790

HQBO1800

HQRO 1810

HQR 01820

HQRO 1830

HQRO 1840

HQR 01850

HQRO 1860

HQR 01870

HQRO 1880

HQEO1890

HQRO 1900

HQR 01910

HQEO 1920

HQRO 01930

HQRO 1940

HQR 01950

HQRO 1960

HQB 01970

HQRO 1980

HQRO 1990

HQR02000

HQRO 2010

HQRO2020

HQEO 2030

HQR 02040

HQRO 2050

HQR02060

HQR 02070

HQRO 2080

HQR 02090

HQR 02100

HQR 02110

HQRO 2120

HQRO2 130

मQK02140

HQRO 2150

HQR. 02160

HQRO 2170

HQRO2 180

HQBO 2190

HQR 02200 
IF (A (NU, NJ-1) .EQ. 0. ODO) GO TO 290

CALL SPLIT $(A, V, N, N U-1, E 1, E 2, N A, N V)$

HQRO 02210

IE (A (NU, NU-1).EQ.0.0DO) GO TC 290

HOEO2220

HQR 02230

$\mathrm{ER}(\mathrm{NU})=\mathrm{E} 1$

$E I(N U-1)=E 2$

ER $(N U-1)=E R(N U)$

$E I(N D)=-E I(N U-1)$

HQR 02240

HOR 02250

HQEO 2260

HQEO 2270

ITYPE $(N U-1)=1$

ITYPE $(N U)=2$

$\mathrm{NU}=\mathrm{NU}-2$

GO TO 300

CONTINUE

$E R(N U)=A(N U, N U)$

$E I(N U)=0.000$

$\mathrm{NU}=\mathrm{NU}-1$

300 CONTINUE

310 CONTINUE

IF (NU.GE.NLON) GO TO 270

HQRO2280

HQRO 2290

HQR 02300

HQRO 2310

HQR 02320

HQRO2330

HQR 02340

HQRO 2350

HQRO2360

$\mathrm{HQRO} 2370$

HQRO2380

HQB 02390

HORO 2400

HQR 02410

HQRO 2420

HQK 02430

END 
C DOUBLE PBECISION A (NA, N),B (NE,H), COND,WORK(N)

C **** LOCAL VARIAELUS:

INTEGER I, J, KIN, KOUT

DOUBLE PKECISION CONDPT.

****SUBROUTINLS CALIED:

DDCOMP, DSULVE

ALI00020

MLIO0030

MLI 00040

ALI00050

HLIO0060

$\triangle L I 00070$

ALI 00080

NL. 100090

MLI00100

MLIOO 110

MLIOO 120

MLIOO 130

$:::::::::::::::::::::::::::::::::::::::::::::::::::::::::::::::::$ MLI00140

ALIOO150

MLIOO 160

MLIO0 170

MLIOO 180

HLIO0190

MLIOO 200

MLI00210

MLI 00220

MLIO I0 230

ALIO0 240

MLI00250

MLIO0260

MLI00270

MLI00280

MLI00290

MLI00300

$\mathrm{NA}, \mathrm{NB}$

N

4

A

B

ON OUTPUT:

B

COND

I PV

WORK
ROW DIHENSIONS OF THE ARRAYS CONTAINING A AND B, RESPECTIVELY, AS DECLAFED IN THE CALLING PROGRAM DIMENSION STATEMENT:

OKDER OF THE MATRIX A AND NUMBEF OP ROWS OF THE MATRIX B;

NUUBER OF COLUMNS OF THE MATEIX B;

N X N COEFFICIENT MATRIX:

$N X$ MIGHT HAND SIDE MATRIX.

SOLUTION MATEIX $X=(A$-INVEESE) *B:

AN ESTIUATE OF THE CONDITION OF A:

PIVOT VECTOR CF LENGTH N (SEE DDCOHP DOCUMENTATION):

A REAL SCBATCH VECTOR OF LENGTH $N$ -
HLIO0 310

HLIO 0320

MLI 100330

MLIOO 340

LLI00350

MLI00360

ALIOO 0370

SLI00 380

HLIO0390

ULI 00400

MLI00410

MLIO0420

aLI 00430

MLI00440

MLI 00450

ALI00460

AL 100470

HLI00480

ALI 00490

AL. 100500

MLIO0510

HLI00 520

MLI00530

ILIO0 540

ALIOOS50 
(1) THE VALUE OE COND SHOULD ALHAYS BE CHECKED BY THE CALLING PKOUKAM. SHOULD A BE NEAR-SINGULAR (OR SINGULAR TO HORKING ACCURACY) THE DATA SHOULD BE INVESTIGATED FOE POSSIBLE ERROKS. IF THERE ARE NONE AND TRE PROBLEM IS APPARENTLY WELL-POSED AND/OR MEANINGPUL, SINGULAR VALUE ANALYSIS IS THEN A MOKE EELIABLE SOLUTION TECHNIQUE (CF. EISPACK SUBEOUTINES SVD AND MINFIT).

(2) MLINEQ CAN BE USED TO COMPUTE THE INVERSE OP A: SIMPLY SOLVE $A * X=I$ WHEEE I IS THE N X I IDETITY MATRIX.

(3) IF THE SOLUTION TO $X * A=B(X=B *(A-I N V E R S E))$ IS DESIEED, SIMPLY TRANSPOSE THE SOLUTION CE

$$
\mathrm{A}^{\mathrm{T}} * \mathrm{X}=\mathrm{B}^{\mathrm{T}}
$$

*****ALGORITHA NOTES:

THE CONTENTS OF A ARE MODIFIED BY THIS SUBROUTINE. SHOULD THE ORIGINAL COEPFICIENTS OF A BE NEEDED SUBSEQUENTLY, THE CONTENTS OF A SHOULD BE SAVED PEIOR TO THE CALL TO MLINEQ.

*****HISTOR Y :

WRITTEN BY ALAN J. LAUB (ELEC. SYS. LAB .. M.T.T.. RH. 35-331, CAMBRIDGE, MA 02139. PH.: (617)-253-2125), AUGUST 1977. MOST KECENT VEESION: SEP. 21, 1977.

MIIOOS60

VLI 00570

MLIO0580

MLI00590

MLI00600

HLIO 00610

MLI 00620

ALI00630

ML. I00640

MLI 00650

HLI00660

MLI00670

MLIO0680

HLI00690

MLI00700

MLI00710

ALI 00720

HLI 00730

GLI00740

MLI00750

ILI00760

ALI00770

HLI00780

MLIO 0790

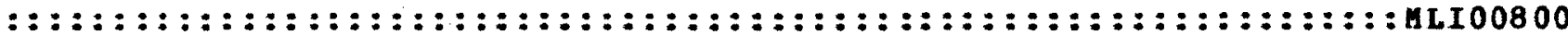

COHHON/INOO/KIN, KOUT

HLI00810

CALL DDCOMP (NA,N,A,COND, I PVT, WORK)

HL. 100820

CONDP $1=$ COND+1. ODO

IF (CONDP 1.GT.COND) GO TO 100

WBITE (KOUT, 44400)

44400

PORMAT (40H1MATRIX RETURN

DO $400 \mathrm{~J}=1, \mathrm{H}$

DO $200 \quad I=1, N$ CONTINUE

$$
\text { VOEK }(I)=B(I, J)
$$

C

COMPUTA (J-TH COLUMN OF $X)=(A-I N V E R S E) *(J-T H$ COLUMN OF B)

CALL DSOLVE (NA, N, A, HORK, IPVT)

DO $300 \quad I=1$, N CONTINUE $B(I, J)=W O K K(I)$

$300 \quad$ CONTINO
$400 \quad$ CONTINUE RETURN

c LAST LINL OF MLINEU

END

MLI00830

MLI 100840

MLI 00850

HLI 00860

ILI 00870

MLI00880

HLI00890

HLI00900

ALI00910

ILI 00920

HLI00930

ELr00940

MLI00950

MLI00960

MLI00970

MLI 00980

LL I00990

ILI01000

MLIO 1010

MLI 01020

MLI 01030

MLI 01040

C 
C

C

C

C

C

c

C

C

C

C

C

C

C

C

c

C

C

C

C

C

C

C

C

C

$c$

C

C

C

C

C

C

C
SULFOUTINA: MULWOA (NA, NE, N,A,B, WOBK)

****\#AKAMETERS:

INIEG

DOUBLI PRECISION A $(N A, N), B(N B, N)$, WOEK (N)

*****LOCAL VAKIABLES:

INTEGEA I,J,K

**** * SUBROUTLINES CALLED:

NCNE

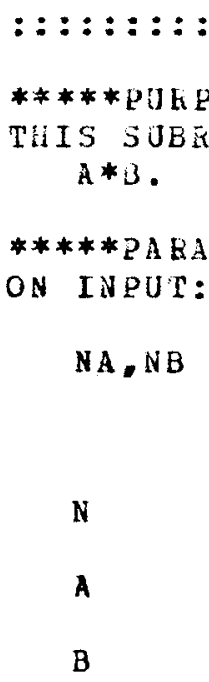

ลUL 00010 MUL00020 MUL00030 MUL 00040 MUL.00050 HUL00060 MUL00070 MUL00080 MUL00090 MUL 00100 MOLOO110 MUL00120 MUL LOO 130 MUL00140 MUI 1.00150 MULOO 160 MULO0 170 MULOO 180 MUL LOO 190 $\triangle 0100200$ MOL 00210 MU L0O220 MU LOO 230 AUL00240 แU L 00250 MUL00260 MUL 00270

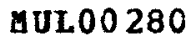
HOL00290 aU L0 0300 MUL00310 AUL 00320 MOL 00330 MUL.00340 MOL 00350 Mu L00360 บU 100370 10200380 HUL00390 BUL00400 MUL00410 MUL.00420 CAMBRN BY ALAN J. LAUB (ELEC. SYS. LAB.. M.I.T., R. 35-331, CAMBRIDGE, YA 02139, PH.: (617)-253-2125), SEPTEMBER 1977. MOST IICENT VERSION: SEP. 21, 1977. $:::::::::::::::::::::::::::::::::::::::::::::::::::::::::::::::::::$ :110L00430 DO $40 \quad I=1, N$ DO $20 \mathrm{~J}=1, \mathrm{~N}$ WOR $K(J)=0.000$ DO $10 \quad K=1, N$ HOEK $(J)=$ HORK $(J)+A(I, K) * B(K, J)$ CONTINUE

CONTINUE DO $30 \mathrm{~J}=1, \mathrm{~N}$ CONTINUE $A(I, J)=\operatorname{HChK}(J)$ CONTINUE
GUL 00450 MUL 200460 10200470 10 L 00480 nOL.00490 HUL00500 AUL 00510 MOL 00520 MULO0 530 MOL00540 MU LOO 550 
M UL 00580

MOL00590

MUL00600 
40 CONTINUE

MOL00560

50 CONTINUE

RETURN

MUL00570

C

C LAST LINE OF MULWOB

GULO0 0580

MU L00590

$\triangle 0 L 00600$

10100610

END

GUL00620 
$c$

C

C $\quad * * * *$ PUNCTIONS :

DOUBLE PEECISION DABS, DSQRT

*****SUBKUUTINES CALLED:

NONE

INTEGSR N,NA, NI, NU, NV

****LOCAL VARIABLES

LOGICAL LAST

INTEG ER I, J,K, NL 2, NL 3, NUM 1

DOU ULI $\mathrm{P}$ HECISION $S, X, Y, Z$
DOUBLE PRECISICN A $(N A, N), P, Q, R, V(N V, N)$

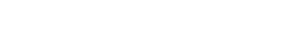

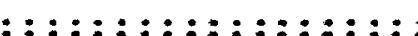

*****PURPOSE:

THIS SUBROUTINE PEEFORMS ONE IMPLICIT QE STEP ON THE UPPER

HESSENBEKG MATRIX A. THE SHIFT IS DETERMINED BY THE NUMBERS $P, Q$. AND $K$. AND THE STEP IS APPLIED TC ROUS AND COLUMNS NL THROUTH NU. THE TRANSFORMATIONS ARE ACCUMOLATED IN THE ARRAY $v$.

*****PARAMETER DESCRIPTION :

ON INPUT:

NA, N V

A

$\mathrm{P}, \mathrm{Q}, \mathrm{R}$

NL

NU

N

ROW DIMENSIONS OP THE ARRAYS CONTAINING A

AND $V$. RESPECTIVELY, AS DECLARED IN THE

CALLING PROGRAA DIHENSION STATEMENT:

N $X$ N UPPER HESSEMBERG MATEIX ON HHICH THE QR STEP IS TO BE PERPOKIED;

PARAMETERS WHICH DETERMINE THE SHIFT;

TÃE LONEE LIMIT OF THE STEP:

THE UPPEB LIMIT OF THE STEP :

OEDER OF THE MATEIX A.

ON OUTPUT:

$$
\text { V }
$$

N X N REAL SCRATCH ARRAY CONTAINING THE ACCUMULATED TBANSFOBMATIONS.

QRSO00 10

QRS 00020

QRSO00 30

QRS 00040

QR S000 50

QRS 00060

QRS00070

QRS 00080

QRSO0090

QRS00100

QRSO0110

QRS0 0120

QBS00130

QRSO0 140

QRS00150

QRSO0 160

QRS00170

QRSO0180

QRS00190

QRS00200

QRS 00210

QRSO0220

QRS00230

QRSO0 240

QRS 00250

QRS00260

QRS00270

QRS00280

QRS 00290

QRS00 300

QRS00310

QRS 00320

QRS00330

QRS 00340

QRS00350

QRS00360

QRS 00370

QRSO0380

QRS 00390

QRSO0 400

QRS00410

QRSOO420

QRS00430

QRSO0 440

QRSO0450

QRS 00460

QR S0 0470

QRS 00480

*****HISTORY:

DOCUMENTED BY J.A.K. CARRIG (ELEC. SYS. LAB., A.I.T..RM. 35-307, CAMBRIDGE, MA 02139 , PH.: (617) - 253-2165) . SEPTEABER 1978.

MOST EECENT VERSION: SEPT $21,1978$.

QR SO 0490

QBS00500

QRS00510

QRS 00520

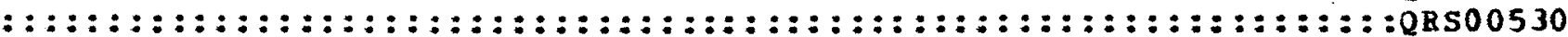

$\mathrm{NL} 2=\mathrm{NL}+2$ 
10

20

30

40

50

60

70

80

90
DO $10 \quad I=N L 2, N U$

$$
A(I, I-2)=0.000
$$

$$
\text { CONTINUE }
$$

IF (NL2.EQ.NO) GC TO 30

NL. $3=N L+3$

DO $20 \quad I=N L 3, N U$

$A(I, I-3)=0.000$

CONTINUE

CONTINUE

NUM $1=N U-1$

DO $130 \quad K=N L$, NOM 1

LAST $=K \cdot E Q$. NUM 1

IF (K.EQ.NL) GO TO 40

$\mathrm{P}=\mathbf{A}(\mathrm{K}, \mathrm{K}-1)$

$2=A(K+1, K-1)$

$\mathrm{R}=0.0 \mathrm{DO}$

IF (. NOT, LAST) $\quad K=A(K+2, K-1)$

$X=D A B S(P)+D A B S(Q)+D A B S(R)$

IF (X.EQ.0.0DU) GO TO 130

$\mathrm{P}=\mathrm{P} / \mathrm{X}$

$Q=Q / X$

$\mathrm{R}=\mathrm{E} / \mathrm{X}$

CONTINUE

$S=D$ SQRT $(P * * 2+Q * * 2+R * * 2)$

IF (P.LT.0.ODO) $S=-S$

IF (K.EQ.NL) GO TO 50

$A(K, K-1)=-5 * X$

GO TO 60

CONTINUE

IF (NL.NE, 1) $A(K, K-1)=-A(K, K-1)$

CONT INUE

$\mathrm{P}=\mathrm{P}+\mathrm{S}$

$\mathrm{X}=\mathrm{P} / \mathrm{S}$

$Y=Q / S$

$\mathrm{Z}=\mathrm{R} / \mathrm{S}$

$\mathrm{Q}=Q / \mathrm{P}$

$\mathrm{K}=\mathrm{k} / \mathrm{P}$

DO $80 \mathrm{~J}=\mathrm{K}, \mathrm{N}$

$\mathrm{P}=\mathrm{A}(K, J)+Q * \mathrm{~A}(K+1, J)$

IF (LAST) GO TO 70

$\mathrm{P}=\mathrm{P}+\mathrm{B} * \mathrm{~A}(\mathrm{~K}+2, \mathrm{~J})$

$A(K+2, J)=A(K+2, J)-P * Z$

CONTINUE

$A(K+1, J)=A(K+1, J)-P * Y$

$A(K, J)=A(K, J)-P * X$

CONTINUE

$J=H I N O(K+3, N U)$

DO $100 \quad I=1, J$

$P=X * A(I, K)+Y * A(I, K+1)$

IF (LAST) GO TO 90

$\mathrm{P}=\mathrm{P}+\mathrm{Z} * \mathrm{~A}(\mathrm{I}, \mathrm{K}+2)$

$A(I, K+2)=A(I, K+2)-P * R$

CONTINUE

$A(I, K+1)=A(I, K+1)-P * Q$

$A(I, K)=A(I, K)-P$
QRSO0560

QRS 00570

QR S00580

QRS 00590

QRSO0600

QRS00610

QRS00620

QRS00630

QRS00640

QRS00650

QRS 00660

QR S00670

QRS00680

QRS00690

QRS00700

QRS 00710

QR 500720

QRS 00730

QR S00740

ORS 00750

QRS 00760

QRS 00770

QRS00780

QR S00790

QRS 00800

QR 500810

QRS 00820

QRS00830

QRS 00840

QRS00850

QRS00860

QRS00870

QRS00880

QRS 00890

QR 500900

QRS 00910

QRS00920

QRS00930

QRS00940

QR S00950

QRS 00960

QRSO0970

QRS 00980

QRS 00990

QRS 01000

QRS01010

QR SO 1020

QRSO 1030

ORS01040

QRS01050

QRSO 1060

QRS 01070

QRSO 1080

QRS 01090

QRSO1100 
100

110

120

130

c

C LASI LINE OF QRSTEP

C END

CONTINUE

DO $120 \quad I=1, N$

$\mathrm{P}=\mathrm{X} * \mathrm{~V}(\mathrm{I}, \mathrm{K})+\mathrm{Y} * \mathrm{~V}(\mathrm{I}, \mathrm{K}+1)$

IF (LAST) GO TO 110

$\mathrm{P}=\mathrm{P}+\mathrm{Z} * \mathrm{~V}(\mathrm{I}, \mathrm{K}+2)$

$V(I, K+2)=V(I, K+2)-P * K$

CONTINUE

$V(I, K+1)=V(I, K+1)-P * Q$

CONTINUE

$V(I, K)=V(I, K)-P$

CONTINUE

RETURN
QR S01110

QRS 01120

QRSO 1130

QRS 01140

QRS01150

QRS 01160

QRSO1170

QRSO 1180

QRS 01190

QRSO 1200

QRSO1210

QRSO 1220

ORS01230

QRS01240

QRS01250

QRS01260 


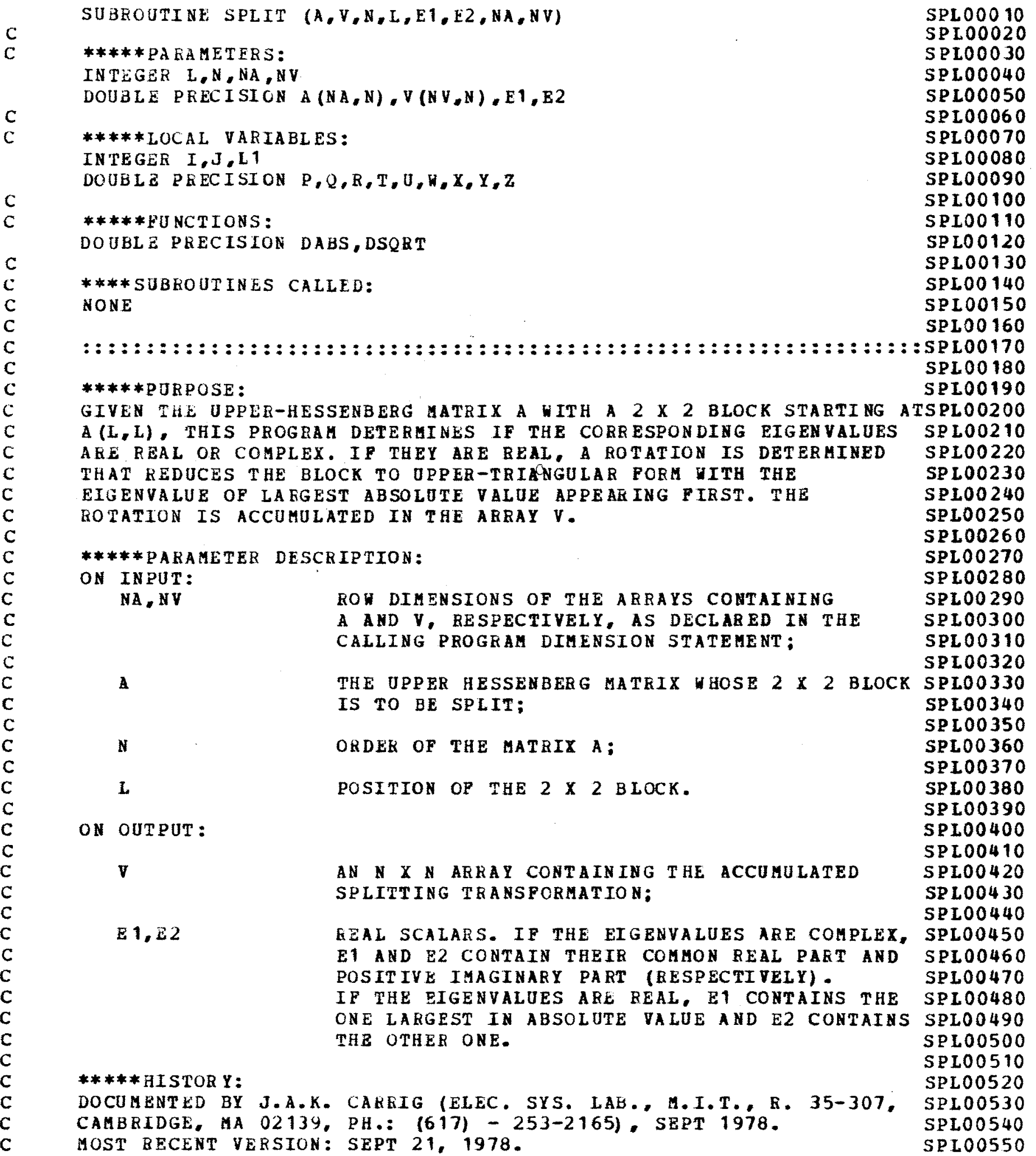


C

$\mathrm{C}$

C

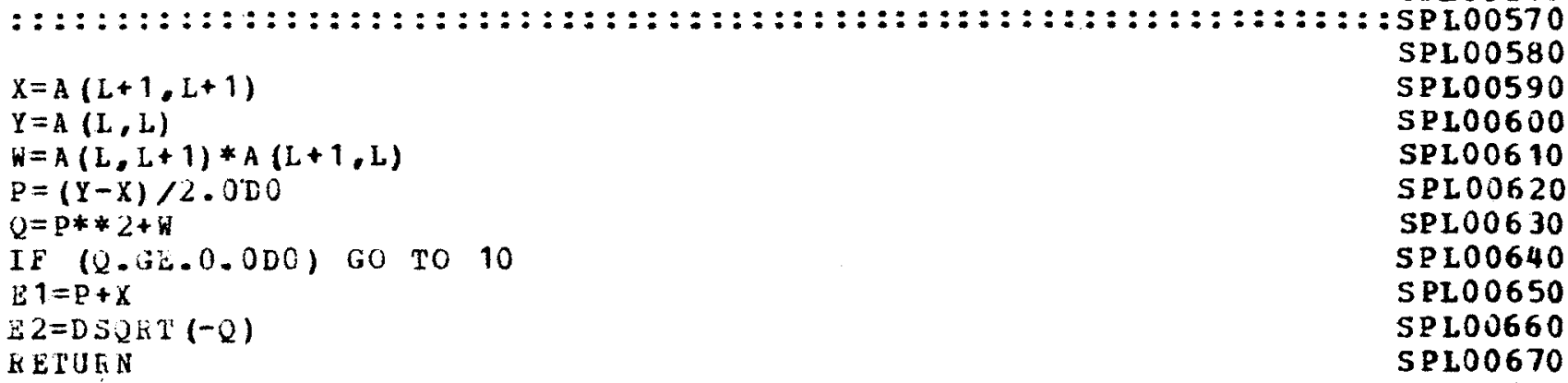

10 CONTINUE.

$z=\operatorname{DSQRT}(\mathrm{Q})$

IF (P.LT.O.ODO) GO TO 20

$\mathrm{z}=\mathrm{p}+\mathrm{z}$

Gu TO 30

20 . CONTINUE

$\mathrm{Z}=\mathrm{p}-\mathrm{Z}$

30 CONTINUE:

IF (Z.EQ.0.000) GO TO 40

$\mathrm{R}=-\mathrm{W} / \mathrm{Z}$

GO TO 50

40 CONTINUE

$\mathrm{R}=0.0 \mathrm{DO}$

50 CONTINUE

IF (DABS $(X+Z)=\operatorname{AE} \cdot \operatorname{DABS}(X+R)) \quad Z=B$

$\mathrm{Y}=\mathrm{Y}-\mathrm{X}-\mathrm{Z}$

$X=-Z$

$T=A(L, L+1)$

$U=A(L+1, L)$

IF (DABS (Y) +DABS (U) . LE.DABS(T)+DABS (X)) GO TO 60

$\mathrm{Q}=\mathrm{U}$

$\mathrm{P}=\Psi$

GO TO 70

60 CONTINUE

$0=x$

$\mathrm{P}=\mathrm{T}$

70 CONTINUE

$\mathrm{E}=\mathrm{DSQRT}(\mathrm{P} * * 2+Q * * 2)$

IF (E.GT.0.0DO) GO TO 80

$E]=A(L, L)$

$E 2=A(L+1, L+1)$

$A(L+1, L)=0.000$

RETUR N

80 CONTINOE

$$
\mathrm{P}=\mathrm{P} / \mathrm{R}
$$

$Q=Q / R$

DO $90 \mathrm{~J}=L, N$

$Z=A(L, J)$

$A(L, J)=P * Z+Q * A(L+1, J)$

$A(L+1, J)=R * A(I+1, J)-Q * Z$

90 CONTINUE

L $1=\mathrm{L}+1$

DO $100 \quad I=1, L 1$

SPLO0580

SPL00590

SPL00600

SPLO06 10

SPL 00620

SPLO06 30

SPL00640

S PL0 0650

SPL00660

SPL00670

SPLO0680

SPLO0690

SPL 00700

SPL00710

SPL 00720

SP L 00730

SPL00740

SP 100750

SPL00760

SPL 00770

SPL00780

SPL 100790

SPLO0800

SPL 00810

SPL00820

SPLO0830

SPL 00840

5 PLOO 850

SPL00860

SPL00870

SPL.00880

SPLO0890

SP L.00900

SPL00910

SPL00920

SPL00930

SPL00940

SPLO0950

SPL00960

SPL00970

SPL00980

SPL00990

SPL01000

SPLO1010

SPLO 1020

SPLO1030

SPLO 1040

SPL 01050

SPLO 1060

SPL01070

SPLO 1080

SPL01090

SPLO 1100 


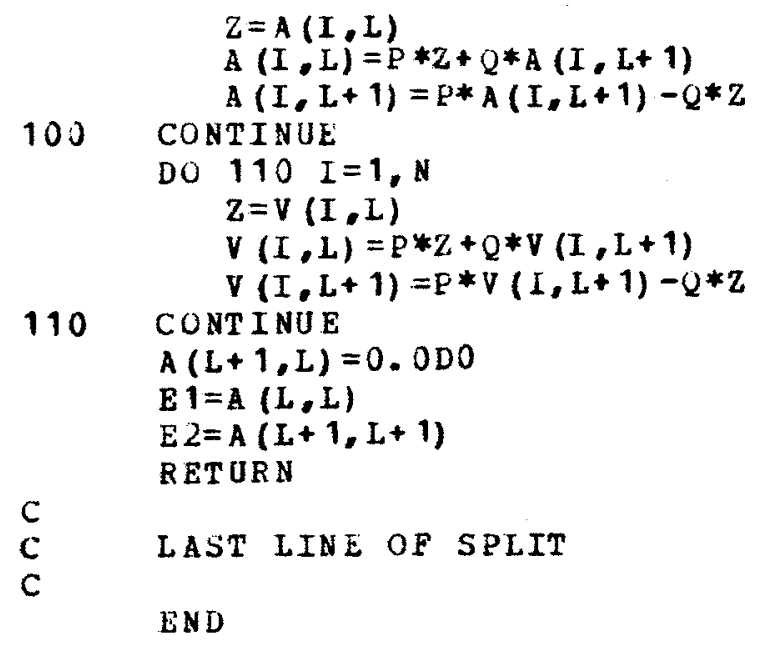

